\title{
ACCF/SCAI/STS/AATS/AHA/ASNC/HFSA/SCCT 2012 appropriate use criteria for coronary revascularization focused update
}

A report of the American College of Cardiology Foundation Appropriate Use Criteria Task Force, Society for Cardiovascular Angiography and Interventions, Society of Thoracic Surgeons, American Association for Thoracic Surgery, American Heart Association, American Society of Nuclear Cardiology, and the Society of Cardiovascular Computed Tomography

Endorsed by the American Society of Echocardiography and the Heart Rhythm Society

Coronary

Revascularization

Writing Group:

Technical Panel:
Manesh R. Patel, MD, FACC, Chair, Gregory J. Dehmer, MD, FACC, FACP, FSCAI, FAHA, ${ }^{*}$ John W. Hirshfeld, MD ${ }^{\dagger}$ Peter K. Smith, MD, FACC, ${ }^{\ddagger}$ and John A. Spertus, MD, MPH, FACC ${ }^{\dagger}$
Appropriate Use Criteria Task Force:
Frederick A. Masoudi, MD, MSPH, FACC, FAHA, Moderator, Gregory J. Dehmer, MD, FACC, FACP, FSCAI, FAHA, Writing Group Liaison, ${ }^{*}$ Manesh R. Patel, MD, FACC, Writing Group Liaison, * Peter K. Smith, MD, FACC, Writing Group Liaison ${ }^{\ddagger}$ Charles E. Chambers, MD, FACC, FSCAI, ${ }^{*}$ T. Bruce Ferguson, Jr, MD, FACC, FAHA ${ }^{\S}$ Mario J. Garcia, MD, FACC, Frederick L. Grover, MD, FACC ${ }^{\S}$ David R. Holmes, Jr, MD, FACC, FSCAI, ${ }^{\dagger}$ Lloyd W. Klein, MD, FACC, FSCAI, FAHA, ${ }^{\dagger}$ Marian C. Limacher, MD, FACC, FACP, FAHA,${ }^{\dagger}$ Michael J. Mack, MD, FACC,${ }^{\S}$ David J. Malenka, MD, FACC, FAHA, ${ }^{\dagger}$ Myung H. Park, MD, FACC, ${ }^{\circledR}$ Michael Ragosta, III, MD, FACC, FSCAI,* James L. Ritchie, MD, FACC, FAHA, ${ }^{\dagger}$ Geoffrey A. Rose, MD, FACC, FASE, ${ }^{\#}$ Alan B. Rosenberg, MD ${ }^{\dagger}$ Andrea M. Russo, MD, FACC, FHRS, ${ }^{* *}$ Richard J. Shemin, MD, FACC, FAHA, ${ }^{\S}$ and William S. Weintraub, MD, FACC, FAHA ${ }^{\dagger \dagger}$ Michael J. Wolk, MD, MACC, Chair, Steven R. Bailey, MD, FACC, FSCAI, FAHA, Pamela S. Douglas, MD, MACC, FAHA, Robert C. Hendel, MD, FACC, FAHA, FASNC, Christopher M. Kramer, MD, FACC, FAHA, James K. Min, MD, FACC, Manesh R. Patel, MD, FACC, Leslee Shaw, PHD, FACC, FASNC, Raymond F. Stainback, MD, FACC, FASE, and Joseph M. Allen, MA

\footnotetext{
*Society for Cardiovascular Angiography and Interventions Representative; ${ }^{\dagger}$ American College of Cardiology Foundation Representative; ${ }^{\dagger}$ Society of Thoracic Surgeons; ${ }^{\S}$ American Association for Thoracic Surgery/Society of Thoracic Surgeons Representative; "Society of Cardiovascular Computed Tomography Representative; "Heart Failure Society of America Representative; "American Society of Echocardiography Representative; ${ }^{* *}$ Heart Rhythm Society Representative; ${ }^{\dagger \dagger}$ American Heart Association Representative.

This document was approved by the American College of Cardiology Foundation Board of Trustees in November 2011.

The American College of Cardiology Foundation requests that this document be cited as follows: Patel MR, Dehmer GJ, Hirshfeld JW, Smith PK, Spertus JA. ACCF/SCAI/STS/AATS/AHA/ASNC/HFSA/SCCT 2012 appropriate use criteria for coronary revascularization focused update: a report of the American College of Cardiology Foundation Appropriate Use Criteria Task Force, Society for Cardiovascular Angiography and Interventions, Society of Thoracic Surgeons,
}

American Association for Thoracic Surgery, American Heart Association, American Society of Nuclear Cardiology, and the Society of Cardiovascular Computed Tomography. J Thorac Cardiovasc Surg. 2012;143:780-803.

Copies: This document is available on the World Wide Web site of the American College of Cardiology (www.cardiosource.org). For copies of this document, please contact Elsevier Inc. Reprint Department, fax (212) 633-3820, E-mail reprints@elsevier.com.

Permissions: Modification, alteration, enhancement, and/or distribution of this document are not permitted without the express permission of the American College of Cardiology Foundation. Please contact Elsevier's permission department at healthpermissions@elsevier.com. $0022-5223 / \$ 36.00$

Copyright (C) 2012 by The American Association for Thoracic Surgery and the American College of Cardiology Foundation doi:10.1016/j.jtcvs.2012.01.061 


\section{TABLE OF CONTENTS}

Abstract. . . . . . . . . . . . . . . . . . . . . 781

Preface . . . . . . . . . . . . . . . . . . . . 782

Introduction . . . . . . . . . . . . . . . . . . . . . . . . . . . . . . . . . . . . .

Methods . . . . . . . . . . . . . . . . . 783

Indication Development . . . . . . . . . . . . . . . . . . . . . . . . 783

Scope of Indications . . . . . . . . . . . . . . . . . . 783

Technical Panel Selection. . . . . . . . . . . . . . . . . 784

Rating Process and Scoring . . . . . . . . . . . . . . . . . . . . . . . . . . . . . . . . . . .

General Assumptions. . . . . . . . . . . . . . . . . . . . . . . . .784

Definitions . . . . . . . . . . . . . . . . . . . . . .785

Maximal Anti-Ischemic Medical Therapy. . . . . . . . . . 785

Stress Testing and Risk of Findings on Noninvasive

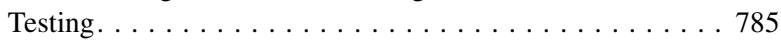

Grading of Angina Pectoris by the Canadian Cardiovascular

Society Classification System 15 . . . . . . . . . . . 786

High-Risk Features for Short-Term Risk of Death or Nonfatal MI

for UA/NSTEMI16 . . . . . . . . . . . . . . . . . . 786

TIMI Risk Score—for Patients With Suspected ACS17 . . 786

Results of Updated Ratings . . . . . . . . . . . . . . . 786

Coronary Revascularization Appropriate Use Criteria (by

Indication) . . . . . . . . . . . . . . . . . . . . . . . .788

Rating Revascularization Methods . . . . . . . . . . . . .795

Mode of Revascularization (Indications 62 to 69) . . . . 795

Discussion . . . . . . . . . . . . . . . . . . . . 795

New Clinical Scenarios to Address Gaps . . . . . . . . . . 795

PCI and CABG in Patients With Multivessel CAD . . . . . 796

Clinical Judgment and Understanding the AUC Ratings. . . 796

Stable Ischemic Heart Disease With Prior CABG . . . . . 796

Application of Criteria. . . . . . . . . . . . . 796

Appendix A: Additional Coronary Revascularization

Definitions . . . . . . . . . . . . . . . . . . . . . . . .797

Angina/Chest Pain Classification. . . . . . . . . . . . . . 797
Invasive Methods of Determining Hemodynamic

Significance . . . . . . . . . . . . . . . . . . . . 797

Appendix B: Additional Methods . . . . . . . . . . . . . . 798

Relationships With Industry and Other Entities. . . . . . 798

Literature Review . . . . . . . . . . . . . . . . . . . . . 798

Appendix C: ACCF/SCAI/STS/AATS/AHA/ASNC/HFSA/

SCCT 2012 Appropriate Use Criteria for Coronary

Revascularization Focused Upda ... . . . . . . . . . . . . . . . 798

Coronary Revascularization Writing Group . . . . . . . . . 798

Coronary Revascularization Technical Panel. . . . . . . . . 798

External Reviewers of the Appropriate Use Criteria

Indications . . . . . . . . . . . . . . . . . . . . . . . . . . 799

ACCF Appropriate Use Criteria Task Force . . . . . . . . . . . 800

Staff . . . . . . . . . . . . . . . . . . . . .883

References..........................803

\section{ABSTRACT}

The American College of Cardiology Foundation (ACCF), Society for Cardiovascular Angiography and Interventions, Society of Thoracic Surgeons, and the American Association for Thoracic Surgery, along with key specialty and subspecialty societies, conducted an update of the appropriate use criteria (AUC) for coronary revascularization frequently considered. In the initial document, 180 clinical scenarios were developed to mimic patient presentations encountered in everyday practice and included information on symptom status, extent of medical therapy, risk level as assessed by noninvasive testing, and coronary anatomy. This update provides a reassessment of clinical scenarios the writing group felt to be affected by significant changes in the medical literature or gaps from prior criteria. The methodology used in this update is similar to the initial document, and the definition of appropriateness was unchanged. The technical panel scored the clinical scenarios on a scale of 1 to 9 . Scores of 7 to 9 indicate that revascularization is considered appropriate and likely to improve patients' health outcomes or survival. Scores of 1 to 3 indicate revascularization is considered inappropriate and unlikely to improve health outcomes or survival. Scores in the mid-range (4 to 6) indicate a clinical scenario for which the likelihood that coronary revascularization will improve health outcomes or survival is uncertain.

In general, as seen with the prior AUC, the use of coronary revascularization for patients with acute coronary syndromes and combinations of significant symptoms and/or ischemia is appropriate. In contrast, revascularization of asymptomatic patients or patients with low-risk findings on noninvasive testing and minimal medical therapy are viewed less favorably. The technical panel felt that based on recent studies, coronary artery bypass grafting remains an appropriate method of revascularization for patients with high burden of coronary artery disease (CAD). Additionally, percutaneous coronary intervention may have a role in revascularization of patients with high burden of CAD. The primary objective of the appropriate use criteria 
is to improve physician decision making and patient education regarding expected benefits from revascularization and to guide future research.

\section{PREFACE}

The American College of Cardiology Foundation (ACCF), in collaboration with the Society for Cardiovascular Angiography and Interventions (SCAI), the Society of Thoracic Surgeons (STS), the American Association for Thoracic Surgery (AATS), and other societies, developed and published in 2009 appropriate use criteria (AUC) for certain clinical scenarios in which coronary revascularization could be used in an effort to address the rational use of coronary revascularization in the delivery of high-quality care. This document is the first focused update of the original document and includes new literature published since the original document and gaps noted during implementation.

The publication of AUC reflects one of several ongoing efforts by the ACCF and its partners to assist clinicians caring for patients with cardiovascular diseases and in support of high-quality cardiovascular care. The ACCF/American Heart Association (AHA) clinical practice guidelines provide a foundation for summarizing evidence-based cardiovascular care and, when evidence is lacking, provide expert consensus opinion that is approved in review by the ACCF and AHA. However, in many areas, variability remains in the use of cardiovascular procedures, raising questions of over- or underuse. The AUC provide a practical standard upon which to assess and better understand variability.

We are grateful to the technical panel and its chair, Frederick A. Masoudi, MD, MSPH, FACC, FAHA, a professional group with a wide range of skills and insights, for their thoughtful and thorough deliberation of the merits of coronary revascularization for various clinical scenarios. We would also like to thank the parent AUC Task Force and the ACCF staff, Joseph M. Allen and Lea Binder, for their exceptionally skilled support in the generation of this document.

\section{Manesh R. Patel, MD, FACC Chair, Coronary Revascularization Writing Group Michael J. Wolk, MD, MACC Chair, Appropriate Use Criteria Task Force}

\section{INTRODUCTION}

This report is a focused update of the AUC for coronary revascularization published in $2009 .{ }^{1}$ The increasing prevalence of coronary artery disease (CAD), continued advances in surgical and percutaneous techniques for revascularization and concomitant medical therapy for $\mathrm{CAD}$, and the costs of revascularization have resulted in heightened interest regarding the appropriate use of coronary revascularization. Clinicians, payers, and patients are interested in the specific benefits of revascularization. Inappropriate revascularization may be harmful to patients and generate unwarranted costs to the healthcare system, whereas appropriate revascularization procedures can improve patients' clinical outcomes.

As in the original AUC document, the same classification scheme with ratings of appropriate, uncertain, and inappropriate was used. The uncertain category can cause confusion in the interpretation of the AUC and can imply several meanings within its definition. First, the rating of uncertain is used when pertinent literature is either not available or when true discrepancies exist. Second, it is impossible to include every relevant piece of clinical information (eg, age, sex, diabetes) in the individual clinical scenarios. Attempting to do that may result in an unmanageable number of clinical scenarios and thus compromise the usefulness of the AUC in daily practice. The practice of medicine is full of uncertainties that require a thoughtful clinician to use his or her best judgment about each patient to reach decisions about management. Therefore, a rating of uncertain may be assigned by members of the technical panel if clinical information not provided might affect their individual rating, causing a shift into either the appropriate or inappropriate category.

A rating of uncertain means simply what the name implies, and depending on additional factors, it can be appropriate or inappropriate to perform revascularization. The writing group emphasizes that uncertain indications are not inappropriate. Rather, they reflect clinical scenarios that are reasonable for performing revascularization, but additional clinical factors should be considered or further research is needed to more definitively define the benefits of treatment for patients.

All prior AUC publications have reflected an ongoing effort to critically and systematically create, review, and categorize the appropriateness of certain cardiovascular diagnostic tests, whereas the AUC for coronary revascularization remains the only document addressing treatment. The writing group and technical panel members for this update are identical to the initial AUC (with only 1 exception) and comprised of members from relevant professional societies including both practicing interventional cardiologists and a cardiothoracic surgeon.

For the majority of clinical scenarios, the technical panel only considered the appropriate use of revascularization irrespective of whether this was accomplished by percutaneous coronary intervention (PCI) or coronary artery bypass graft surgery (CABG). However, in a select subgroup of clinical scenarios in which revascularization is generally considered appropriate, the appropriateness of PCI and $\mathrm{CABG}$, individually, was considered. In this subgroup, it was recognized that a focused update could be necessary following publication of the SYNTAX (Synergy Between PCI With TAXUS and Cardiac Surgery) trial. ${ }^{2}$ Therefore, in this update, the writing group identified 4 indications possibly affected by results of the SYNTAX trial for 
reexamination. The writing group also split 2 of the indications to represent levels of disease burden, recognizing, however, that the ability to reproducibly quantify the SYNTAX score in routine clinical practice has challenges. Also in this subgroup, the variables of diabetes and depressed left ventricular function were included in the initial AUC, but these were combined for the update because all indications with these variables were rated the same in the previous scores by the technical panel.

In addition, since the publication of the original document, efforts to implement data collection protocols related to the AUC indications identified a gap in the clinical scenarios related to lower-risk unstable angina/non-STsegment elevation myocardial infarction (UA/NSTEMI) patients and asymptomatic patients with 1- or 2-vessel CAD not involving the proximal left anterior descending artery (LAD) in whom no noninvasive testing had been performed. Although limited new evidence is available for these patient populations since publication, the writing group developed indications to address these previous omissions.

\section{METHODS}

A detailed description of the methods used for rating the selected clinical indications is found in a previous publication, "ACCF Proposed Method for Evaluating the Appropriateness of Cardiovascular Imaging." 3 Briefly, this process combines evidence-based medicine and practice experience by engaging a technical panel in a modified Delphi exercise. The technical panel is created from nominations given by multiple relevant professional societies and provider-led organizations as well as from health policy and payer communities. To preserve objectivity, technical panels are created so as to not include a majority of individuals whose livelihood is tied to the technology under evaluation.

In making its appropriate use determinations, the technical panel is provided with summaries of the relevant evidence from the medical literature and practice guidelines. Panelists are first asked individually, and then collectively, to assess the benefits and risks of a test or procedure in the context of the potential benefits to patients' outcomes and an implicit understanding of the associated resource use and costs. After the rating process, the final appropriate use ratings are summarized using an established rigorous methodology. ${ }^{4}$

\section{Indication Development}

Appropriate use criteria are based on current understanding of the technical capabilities and potential patient benefits of the procedures examined. The AUC are also developed to identify common clinical scenarios-but they cannot possibly include every conceivable patient presentation. The term indication is used interchangeably with clinical scenario in the document for brevity and does not imply that a procedure should necessarily be performed. Some patients seen in clinical practice are not represented in these appropriate use criteria or have additional extenuating features that would alter the appropriateness of treatment as compared with the clinical scenarios presented. Additionally, although AUC indications and ratings are shaped by the guidelines, the AUC often contain more detailed clinical scenarios than the more generalized situations covered in clinical practice guidelines, and thus, subtle differences between these 2 guidance tools may be possible. To minimize this possibility, the coronary revascularization criteria were updated in conjunction with members of the ACCF/AHA PCI and CABG revascularization guideline committees.

Appropriate use criteria are intended to assist patients and clinicians, but are not intended to diminish the acknowledged difficulty or uncertainty of clinical decision making and cannot act as substitutes for sound clinical judgment and practice experience. Rather, the aim of these criteria is to allow assessment of utilization patterns for a test or procedure. Comparing utilization patterns across a large subset of provider's patients can allow for an assessment of a provider's management strategies with those of his/her peers. The ACCF and its collaborators believe that an ongoing review of one's practice using these criteria will help guide a more effective, efficient, and equitable allocation of healthcare resources, and ultimately, better patient outcomes.

The indications went through external review by multisociety and specialty representation for the 2009 document. Because of the narrow focus, the indications were not sent for external review for this update.

\section{Scope of Indications}

As previously described, the indications for coronary revascularization were developed considering the following common variables:

a. The clinical presentation (eg, acute coronary syndrome, stable angina);

b. Severity of angina (asymptomatic, Canadian Cardiovascular Society [CCS] Class I, II, III, or IV);

c. Extent of ischemia on noninvasive testing and the presence or absence of other prognostic factors, such as congestive heart failure, depressed left ventricular function, or diabetes;

d. Extent of medical therapy; and

e. Extent of anatomic disease (1-, 2-, 3-vessel disease, with or without proximal LAD or left main coronary disease).

The clinical scenarios developed include coronary anatomy, as this is the focus of much of the previous literature on coronary revascularization. However, the writing group recognizes that for everyday patient care, symptom status, ischemic burden, and level of medical therapy often play 
a critical role in decision making even before the coronary anatomy has been defined by angiography. It is important to note that the indications focus on revascularization, percutaneous or surgical, and do not address diagnostic catheterization or coronary angiography; these criteria are currently under development.

\section{Technical Panel Selection}

Stakeholders were given the opportunity to participate in the AUC process by submitting nominees from their organizations through a call for nominations announced in the summer of 2006. From this list of nominees, the AUC Task Force and writing group selected technical panel members to ensure an appropriate balance with respect to expertise. The 17-member technical panel was composed of 4 interventional cardiologists, 4 cardiovascular surgeons, 8 members representing noninterventional cardiologists, other physicians who treat patients with cardiovascular disease, health outcome researchers, and 1 medical officer from a health plan. For the update of the AUC for coronary revascularization, the same technical panelists (with 1 exception) from the original document published in 2009 were reconvened to rerate the 15 clinical scenarios included in the focused update.

\section{Rating Process and Scoring}

The technical panel members first rated indications independently. Then, the technical panel participated in 2 conferences calls for a discussion of each indication. After the discussion, panelists independently provided their final scores for each indication. Each panelist had equal weight in producing the final result for the indications and was not forced into consensus. For each indication, the median numerical score was determined and then assigned to an appropriate use category.

For the conference calls, each technical panelist received a personalized rating form that indicated his/her rating for each indication and the distribution of de-identified ratings of other members of the panel. In addition, the moderator received a summary rating form with similar information (including panelist identification), along with other statistics reflecting the level of agreement among technical panel members. The level of agreement among panelists, as defined by RAND, was analyzed for each indication based on the BIOMED rule for a panel of 14 to 16 (a simplified RAND method for determining disagreement). ${ }^{4}$ Per the BIOMED definition, agreement was defined as an indication where 4 or fewer panelists' ratings fell outside the 3-point region containing the median score. Disagreement was defined as a situation where at least 5 panelists' ratings fell in both the appropriate and the inappropriate categories. Because the technical panel had 17 representatives, which exceeded the 16 addressed in this rule, an additional level of agreement analysis as described by RAND was performed that examined the interpercentile range compared with interpercentile range adjusted for symmetry. ${ }^{4}$ This information was used by the moderator to guide the technical panel's discussion by highlighting areas of differences among the panelists.

In developing these appropriate use criteria for coronary revascularization, the technical panel was asked to assess whether coronary revascularization for each indication was appropriate, uncertain, or inappropriate using the following definition of appropriate use:

Coronary revascularization is appropriate when the expected benefits, in terms of survival or health outcomes (symptoms, functional status, and/or quality of life) exceed the expected negative consequences of the procedure.

The technical panel scored each indication on a scale from 1 to 9 as follows:

\section{Median Score 7 to 9}

Appropriate procedure for specific indication (procedure is generally acceptable and is a reasonable approach for the indication).

Median Score 4 to 6

Uncertain for specific indication (procedure may be generally acceptable and may be a reasonable approach for the indication). Uncertainty implies that more research and/or patient information is needed to classify the indication definitively.

\section{Median Score 1 to 3}

Inappropriate procedure for that indication (procedure is not generally acceptable and is not a reasonable approach for the indication).

The division of these scores into 3 levels of appropriateness is somewhat arbitrary, and the numeric designations should be viewed as a continuum. Further, there is diversity in clinical opinion for particular clinical scenarios, such that scores in the intermediate level of appropriateness should be labeled uncertain, because critical patient or research data may be lacking or discordant. This designation serves as a prompt to the field to carry out definitive research investigations whenever possible. It is anticipated that the AUC reports will continue to be revised as further data are generated and information from the implementation of the criteria is accumulated.

To prevent bias in the scoring process, care was taken in providing objective, nonbiased information, including guidelines and key references, to the technical panel.

\section{GENERAL ASSUMPTIONS}

Specific assumptions are provided that were considered by the technical panel in rating the relevant clinical scenarios for the appropriate use of revascularization:

1. Each clinical scenario includes the patient's clinical status/symptom complex, ischemic burden by noninvasive functional testing when presented, burden of coronary 
atherosclerosis as determined by angiography, and intensity of medical therapy in the determination of the appropriate use of coronary revascularization.

2. Assume coronary angiography has been performed when these findings are presented in the indications. The technical panel should rate the appropriateness of revascularization based upon the clinical features and coronary findings, and not the appropriateness of diagnostic coronary angiography.

3. Assume left main coronary artery stenosis (greater than or equal to $50 \%$ luminal diameter narrowing) or proximal LAD stenosis (greater than or equal to $70 \%$ luminal diameter narrowing) is not present unless specifically noted. Assume no other significant coronary artery stenoses are present except those noted in the clinical scenario.

4. The clinical scenarios should be rated based on the published literature regarding the risks and benefits of percutaneous and surgical coronary revascularization. Note that specific patient groups not well represented in the literature are not presented in the current clinical scenarios. However, the writing group recognizes that decisions about coronary artery revascularization in such patients are frequently required. Examples of such patients include those with end-stage renal disease or advanced age.

5. Clinical outcome is related to the extent of coronary artery disease (Table A1). ${ }^{5}$ Based on this observation and clinical guideline recommendations regarding "borderline" angiographic stenosis (50\% to 60\%) in epicardial (non-left main) locations, a significant coronary stenosis for the purpose of the clinical scenarios is defined as:

- Greater than or equal to $70 \%$ luminal diameter narrowing, by visual assessment, of an epicardial stenosis measured in the "worst view" angiographic projection.

- Greater than or equal to $50 \%$ luminal diameter narrowing, by visual assessment, of a left main stenosis measured in the "worst view" angiographic projection.

6. All patients are receiving standard care, including guideline-based risk factor modification for primary or secondary prevention in cardiovascular patients unless specifically noted. ${ }^{6-10}$

7. Despite the best efforts of the clinician, all patients may not achieve target goals for risk factor modification. However, a plan of care to address risk factors is assumed to be occurring in patients represented in the indications. For patients with chronic stable angina, the writing group recognizes that there is a wide variance in the medical therapy for angina. The specific definition of maximal anti-ischemic medical therapy is presented in the definition section and includes the use of 2 or more antianginal medications.

8. Operators performing percutaneous or surgical revascularization have appropriate clinical training and experi-
TABLE A1. CAD prognostic index

\begin{tabular}{lcc}
\hline \multicolumn{1}{c}{ Extent of CAD } & $\begin{array}{c}\text { Prognostic } \\
\text { weight }(\mathbf{0 - 1 0 0})\end{array}$ & $\begin{array}{c}\text { 5-Year survival } \\
\text { rate (\%)* }\end{array}$ \\
\hline 1-vessel disease, $75 \%$ & 23 & 93 \\
$>$ 1-vessel disease, $50 \%$ to 74\% & 23 & 93 \\
1-vessel disease, $\geq 95 \%$ & 32 & 91 \\
2-vessel disease & 37 & 88 \\
2-vessel disease, both $\geq 95 \%$ & 42 & 86 \\
1-vessel disease, $\geq 95 \%$ proximal LAD & 48 & 83 \\
2-vessel disease, $\geq 95 \%$ LAD & 48 & 83 \\
2-vessel disease, $\geq 95 \%$ proximal LAD & 56 & 79 \\
3-vessel disease & 56 & 79 \\
3-vessel disease, $\geq 95 \%$ in at least 1 & 63 & 73 \\
3-vessel disease, 75\% proximal LAD & 67 & 67 \\
3-vessel disease, $\geq 95 \%$ proximal LAD & 74 & 59 \\
\hline
\end{tabular}

$C A D$, Coronary artery disease; $L A D$, left anterior descending coronary artery

*Assuming medical treatment only. Reprinted with permission from Califf et al. ${ }^{5}$

ence and have satisfactory outcomes as assessed by quality assurance monitoring. ${ }^{11-13}$

9. Revascularization by either percutaneous or surgical methods is performed in a manner consistent with established standards of care. ${ }^{11-13}$

10. In the clinical scenarios, no unusual extenuating circumstances exist (such as inability to comply with antiplatelet agents, do not resuscitate status, patient unwilling to consider revascularization, technically not feasible to perform revascularization, or comorbidities likely to markedly increase procedural risk substantially) unless specifically noted.

\section{DEFINITIONS}

A complete set of definitions of terms used throughout the clinical scenarios is listed in Appendix A. These definitions were provided to and discussed with the technical panel prior to the rating of indications.

\section{Maximal Anti-Ischemic Medical Therapy}

As previously stated, the indications assume that patients are receiving risk factor modification according to guideline-based recommendations. For the purposes of the clinical scenarios presented, maximal antianginal medical therapy is defined as the use of at least 2 classes of therapies to reduce anginal symptoms.

\section{Stress Testing and Risk of Findings on Noninvasive Testing}

Stress testing is commonly used for both diagnosis and risk stratification of patients with coronary artery disease. Using criteria defined for traditional exercise stress tests ${ }^{14}$ :

Low-risk stress test findings: associated with a cardiac mortality of less than $1 \%$ per year 
Intermediate-risk stress test findings: associated with a $1 \%$ to $3 \%$ per year cardiac mortality

High-risk stress test findings: associated with a greater than $3 \%$ per year cardiac mortality

Examples of findings from noninvasive studies and their associated level of risk for cardiac mortality are presented in Table A2. ${ }^{13}$ As noted in the footnote to this table, for certain low-risk findings, there may be additional findings that alter the assessment of risk, but these relationships have not been well studied. Implicit in these risk definitions is a measure of the amount of myocardium at risk, or ischemic myocardium. For the purpose of the indications for coronary revascularization, stress test findings are presented by these risk criteria. For patients without stress test findings, please refer to the note below on invasive methods of determining hemodynamic significance. Assume that when prior testing (including an imaging procedure) is referenced in an indication, the testing was performed correctly and with sufficient quality so as to produce a meaningful and accurate result within the limits of the test performance.

For the purposes of the clinical scenarios in this document, patients with both typical and atypical angina are classified by the feature of the CCS grading system presented below. Patients with noncardiac chest pain should be considered to be asymptomatic.

\section{Grading of Angina Pectoris by the Canadian Cardiovascular Society Classification System ${ }^{15}$}

Class I: Ordinary physical activity does not cause angina, such as walking, climbing stairs. Angina occurs with strenuous, rapid, or prolonged exertion at work or recreation.

Class II: Slight limitation of ordinary activity. Angina occurs on walking more than 2 blocks on the level and climbing more than 1 flight of ordinary stairs at a normal pace and in normal condition.

Class III: Marked limitations of ordinary physical activity. Angina occurs on walking 1 or 2 blocks on the level and climbing 1 flight of stairs in normal conditions and at a normal pace.

Class IV: Inability to carry on any physical activity without discomfort_-anginal symptoms may be present at rest.

\section{High-Risk Features for Short-Term Risk of Death or} Nonfatal MI for UA/NSTEMI ${ }^{16}$

At least 1 of the following:

- History-accelerating tempo of ischemic symptoms in preceding 48 hours

- Character of pain-prolonged ongoing (greater than 20 minutes) rest pain
- Clinical findings

- Pulmonary edema, most likely due to ischemia

- New or worsening mitral regurgitation murmur

- $\mathrm{S}_{3}$ or new/worsening rales

- Hypotension, bradycardia, tachycardia

- Age greater than 75 years

- Electrocardiogram

- Angina at rest with transient ST-segment changes greater than $0.5 \mathrm{~mm}$

- Bundle-branch block, new or presumed new

- Sustained ventricular tachycardia

- Cardiac marker

- Elevated cardiac TnT, TnI, or CK-MB (eg, TnT or TnI greater than $0.1 \mathrm{ng}$ per $\mathrm{mL}$ )

TIMI Risk Score-for Patients With Suspected $\mathrm{ACS}^{17}$

Variables (1 point each)

- Age $\geq 65$ years

- $\geq 3$ risk factors (hypertension, diabetes mellitus, family history, lipids, smoking)

- Known CAD (stenosis $\geq 50 \%$ )

- Aspirin use in past 7 days

- Severe angina ( $\geq 2$ episodes within 24 hours)

- ST-segment deviation $\geq 0.5 \mathrm{~mm}$

- Elevated cardiac markers

Risk of death or ischemic event through 14 days

- Low: 0-2 (<8.3\% event rate)

- Intermediate: 3-4 (<19.3\% event rate)

- High: 5-7 (41\% event rate)

\section{RESULTS OF UPDATED RATINGS}

The writing group evaluated the previous 180 clinical scenarios and identified those where reevaluation, expansion, or consolidation was felt necessary (Table A). Nine of the 15 updated indications met the definition of agreement as described above. There were no ratings where the technical panel held such opposing viewpoints that the technical panel's votes were determined to be in "disagreement" as defined by the strict RAND definitions and described previously in the Methods section.

As the majority of the original clinical scenarios and ratings were not rerated in this update, Table A represents the focused update indications. In addition, the entire list of 171 clinical scenarios and their appropriateness scores are shown below in Tables 1, 2, 3, and 4. Figures 1, 2, 3, 4 , and 5 demonstrate gradients in appropriate use rating by increasingly severe symptom status and ischemic risk, and by the method of revascularization. These are also 
TABLE A. Focused update: new or revised indications

\section{Patients With Acute Coronary Syndromes}

9. - UA/NSTEMI and low-risk features (eg, TIMI score $\leq 2$ ) for short-term risk of death or nonfatal MI

- Revascularization of the presumed culprit artery

10. - UA/NSTEMI and intermediate-risk features (eg, TIMI score 3-4) for short-term risk of death or nonfatal MI

- Revascularization of the presumed culprit artery

\section{Patients Without Prior Bypass Surgery Asymptomatic}

20. - One- or 2-vessel CAD without involvement of proximal LAD

- No noninvasive testing performed

Method of Revascularization: Multivessel CAD, CCS Angina Greater Than or Equal to Class III, and/or Evidence of Intermediate- to High-Risk Findings on Noninvasive Testing

\begin{tabular}{|c|c|c|c|}
\hline 62. & - Two-vessel CAD with proximal LAD stenosis & $\mathbf{A}(7)$ & $\mathbf{A}(\mathbf{8})$ \\
\hline 63. & - Three-vessel CAD with low CAD burden (eg, 3 focal stenoses, low SYNTAX score) & A (7) & A (9) \\
\hline 64. & $\begin{array}{l}\text { - Three-vessel CAD with intermediate to high CAD burden (eg, multiple diffuse lesions, presence of } \\
\text { CTO, or high SYNTAX score) }\end{array}$ & $\mathbf{U}(4)$ & $\mathbf{A}(\mathbf{9})$ \\
\hline 65 . & - Isolated left main stenosis & $\mathbf{U}(6)$ & $\mathbf{A}(\mathbf{9})$ \\
\hline 66. & $\begin{array}{l}\text { - Left main stenosis and additional CAD with low CAD burden (eg, 1- to 2-vessel additional involvement, } \\
\text { low SYNTAX score) }\end{array}$ & $\mathbf{U}(\mathbf{5})$ & $\mathbf{A}(\mathbf{9})$ \\
\hline 67. & $\begin{array}{l}\text { - Left main stenosis and additional CAD with intermediate to high CAD burden (eg, 3-vessel } \\
\text { involvement, presence of CTO, or high SYNTAX score) }\end{array}$ & I (3) & $\mathbf{A}(\mathbf{9})$ \\
\hline
\end{tabular}

presented in a format similar to the original document. In addition to the changes reflected in Table $\mathrm{A}$, the fractional flow reserve (FFR) cut point was updated from 0.75 to
0.80 in indication 22 to reflect new literature since the publication of the original document and to maintain consistency with guidelines. ${ }^{18}$ 


\section{CORONARY REVASCULARIZATION APPROPRIATE USE CRITERIA (BY INDICATION)}

TABLE 1. Patients with acute coronary syndromes

\begin{tabular}{|c|c|c|}
\hline \multicolumn{2}{|c|}{ Indication } & \multirow{2}{*}{$\begin{array}{l}\text { Appropriate Use } \\
\text { Score (1-9) } \\
\text { A (9) }\end{array}$} \\
\hline 1. & $\begin{array}{l}\text { - STEMI } \\
\text { - Less than or equal to } 12 \text { hours from onset of symptoms } \\
\text { - Revascularization of the culprit artery }\end{array}$ & \\
\hline 2. & $\begin{array}{l}\text { - STEMI } \\
\text { - Onset of symptoms within the prior } 12 \text { to } 24 \text { hours } \\
\text { - Severe HF, persistent ischemic symptoms, or hemodynamic or electrical instability present }\end{array}$ & $A(9)$ \\
\hline 3. & $\begin{array}{l}\text { - STEMI } \\
\text { - Greater than } 12 \text { hours from symptom onset } \\
\text { - Asymptomatic; no hemodynamic instability and no electrical instability }\end{array}$ & I (3) \\
\hline 4. & $\begin{array}{l}\text { - STEMI with presumed successful treatment with fibrinolysis } \\
\text { - Evidence of HF, recurrent ischemia, or unstable ventricular arrhythmias present } \\
\text { - One-vessel CAD presumed to be the culprit artery }\end{array}$ & $A(9)$ \\
\hline 5. & $\begin{array}{l}\text { - STEMI with presumed successful treatment with fibrinolysis } \\
\text { - Asymptomatic; no HF or no recurrent ischemic symptoms, or no unstable ventricular arrhythmias } \\
\text { - Normal LVEF } \\
\text { - One-vessel CAD presumed to be the culprit artery }\end{array}$ & U (5) \\
\hline 6. & $\begin{array}{l}\text { - STEMI with presumed successful treatment with fibrinolysis } \\
\text { - Asymptomatic; no HF, no recurrent ischemic symptoms, or no unstable ventricular arrhythmias at time of presentation } \\
\text { - Depressed LVEF } \\
\text { - Three-vessel CAD } \\
\text { - Elective/semielective revascularization }\end{array}$ & A (8) \\
\hline 7. & $\begin{array}{l}\text { - STEMI with successful treatment of the culprit artery by primary PCI or fibrinolysis } \\
\text { - Asymptomatic; no HF, no evidence of recurrent or provokable ischemia, or no unstable ventricular arrhythmias during } \\
\text { index hospitalization } \\
\text { - Normal LVEF } \\
\text { - Revascularization of a non-infarct-related artery during index hospitalization }\end{array}$ & I (2) \\
\hline 8. & $\begin{array}{l}\text { - STEMI or NSTEMI and successful PCI of culprit artery during index hospitalization } \\
\text { - Symptoms of recurrent myocardial ischemia and/or high-risk findings on noninvasive stress testing performed after } \\
\text { index hospitalization } \\
\text { - Revascularization of } \geq 1 \text { additional coronary arteries }\end{array}$ & $A(8)$ \\
\hline 9. & $\begin{array}{l}\text { - UA/NSTEMI and low-risk features (e g, TIMI score } \leq 2 \text { ) for short-term risk of death or nonfatal MI } \\
\text { - Revascularization of the presumed culprit artery }\end{array}$ & $U(6)$ \\
\hline 10. & $\begin{array}{l}\text { - UA/NSTEMI and intermediate-risk features (eg, TIMI score 3-4) for short-term risk of death or nonfatal MI } \\
\text { - Revascularization of the presumed culprit artery }\end{array}$ & $A(8)$ \\
\hline 11. & $\begin{array}{l}\text { - UA/NSTEMI and high-risk features for short-term risk of death or nonfatal MI } \\
\text { - Revascularization of the presumed culprit artery }\end{array}$ & A (9) \\
\hline 12. & $\begin{array}{l}\text { - UA/NSTEMI and high-risk features for short-term risk of death or nonfatal MI } \\
\text { - Revascularization of multiple coronary arteries when the culprit artery cannot clearly be determined }\end{array}$ & A (9) \\
\hline 13. & $\begin{array}{l}\text { - Patients with acute myocardial infarction (STEMI or NSTEMI) } \\
\text { - Evidence of cardiogenic shock } \\
\text { - Revascularization of } \geq 1 \text { coronary arteries }\end{array}$ & $A(8)$ \\
\hline
\end{tabular}

New and updated indications are shaded blue. $A$, Appropriate; $C A D$, coronary artery disease; $H F$, heart failure; $I$, inappropriate; $L V E F$, left ventricular ejection fraction; $M I$, myocardial infarction; NSTEMI, non-ST-segment elevation myocardial infarction; PCI, percutaneous coronary intervention; STEMI, ST-segment elevation myocardial infarction; $T I M I$, Thrombolysis In Myocardial Infarction; $U$, uncertain; $U A$, unstable angina. 
TABLE 2. Patients without prior bypass surgery

\begin{tabular}{|c|c|c|c|c|}
\hline \multicolumn{2}{|c|}{ Indication } & \multicolumn{3}{|c|}{ Appropriate Use Score (1-9) } \\
\hline \multicolumn{2}{|r|}{ ccs Angina Class } & Asymptomatic & I or II & III or IV \\
\hline 14. & $\begin{array}{l}\text { - One- or 2-vessel CAD without involvement of proximal LAD } \\
\text { - Low-risk findings on noninvasive testing } \\
\text { - Receiving no or minimal anti-ischemic medical therapy }\end{array}$ & I (1) & I (2) & $U(5)$ \\
\hline 15. & $\begin{array}{l}\text { - One- or 2-vessel CAD without involvement of proximal LAD } \\
\text { - Low-risk findings on noninvasive testing } \\
\text { - Receiving a course of maximal anti-ischemic medical therapy }\end{array}$ & I (2) & U (5) & A (7) \\
\hline 16. & $\begin{array}{l}\text { - One- or 2-vessel CAD without involvement of proximal LAD } \\
\text { - Intermediate-risk findings on noninvasive testing } \\
\text { - Receiving no or minimal anti-ischemic medical therapy }\end{array}$ & I (3) & U (5) & $U(6)$ \\
\hline 17. & $\begin{array}{l}\text { - One- or 2-vessel CAD without involvement of proximal LAD } \\
\text { - Intermediate-risk findings on noninvasive testing } \\
\text { - Receiving a course of maximal anti-ischemic medical therapy }\end{array}$ & U (4) & $A(7)$ & $A(8)$ \\
\hline 18. & $\begin{array}{l}\text { - One- or 2-vessel CAD without involvement of proximal LAD } \\
\text { - High-risk findings on noninvasive testing } \\
\text { - Receiving no or minimal anti-ischemic medical therapy }\end{array}$ & $U(6)$ & $A(7)$ & A (8) \\
\hline 19. & $\begin{array}{l}\text { - One- or 2-vessel CAD without involvement of proximal LAD } \\
\text { - High-risk findings on noninvasive testing } \\
\text { - Receiving a course of maximal anti-ischemic medical therapy }\end{array}$ & $A(7)$ & $A(8)$ & $A(9)$ \\
\hline 20. & $\begin{array}{l}\text { - One- or 2-vessel CAD without involvement of proximal LAD } \\
\text { - No noninvasive testing performed }\end{array}$ & $I(3)$ & $U(5)$ & $A(7)$ \\
\hline 21. & $\begin{array}{l}\text { - One- or 2-vessel CAD with borderline stenosis " } 50 \% \text { to } 60 \% \text { " } \\
\text { - No noninvasive testing performed } \\
\text { - No further invasive evaluation performed (ie, FFR, IVUS) }\end{array}$ & Not rated & I (2) & I (3) \\
\hline 22. & $\begin{array}{l}\text { - One- or 2-vessel CAD with borderline stenosis " } 50 \% \text { to } 60 \% \text { " } \\
\text { - No noninvasive testing performed or equivocal test results present } \\
\text { - FFR less than or equal to } 0.80 * \text { and/or IVUS with significant reduction in } \\
\text { cross-sectional area }\end{array}$ & I (3) & $U(6)$ & A (7) \\
\hline 23. & $\begin{array}{l}\text { - One- or 2-vessel CAD with borderline stenosis " } 50 \% \text { to } 60 \% \text { " } \\
\text { - No noninvasive testing performed or equivocal test results present } \\
\text { - FFR or IVUS findings do not meet criteria for significant stenosis }\end{array}$ & I (1) & I (2) & I (2) \\
\hline 24. & $\begin{array}{l}\text { - Chronic total occlusion of } 1 \text { major epicardial coronary artery, without other } \\
\text { coronary stenoses } \\
\text { - Low-risk findings on noninvasive testing } \\
\text { - Receiving no or minimal anti-ischemic medical therapy }\end{array}$ & $I(1)$ & $I(2)$ & $I(3)$ \\
\hline 25. & $\begin{array}{l}\text { - Chronic total occlusion of } 1 \text { major epicardial coronary artery, without other } \\
\text { coronary stenoses } \\
\text { - Low-risk findings on noninvasive testing } \\
\text { - Receiving a course of maximal anti-ischemic medical therapy }\end{array}$ & I (1) & U (4) & $U(6)$ \\
\hline 26. & $\begin{array}{l}\text { - Chronic total occlusion of } 1 \text { major epicardial coronary artery, without other } \\
\text { coronary stenoses } \\
\text { - Intermediate-risk findings on noninvasive testing } \\
\text { - Receiving no or minimal anti-ischemic medical therapy }\end{array}$ & I (3) & U (4) & $U(6)$ \\
\hline 27. & $\begin{array}{l}\text { - Chronic total occlusion of } 1 \text { major epicardial coronary artery, without other } \\
\text { coronary stenoses } \\
\text { - Intermediate-risk criteria on noninvasive testing } \\
\text { - Receiving a course of maximal anti-ischemic medical therapy }\end{array}$ & U (4) & $U(5)$ & A (7) \\
\hline 28. & $\begin{array}{l}\text { - Chronic total occlusion of } 1 \text { major epicardial coronary artery, without other } \\
\text { coronary stenoses } \\
\text { - High-risk findings on noninvasive testing } \\
\text { - Receiving no or minimal anti-ischemic medical therapy }\end{array}$ & U (4) & $U(5)$ & $A(7)$ \\
\hline 29. & $\begin{array}{l}\text { - Chronic total occlusion of } 1 \text { major epicardial coronary artery, without other } \\
\text { coronary stenoses } \\
\text { - High-risk criteria on noninvasive testing } \\
\text { - Receiving a course of maximal anti-ischemic medical therapy }\end{array}$ & $U(5)$ & $A(7)$ & $A(8)$ \\
\hline 30. & $\begin{array}{l}\text { - One-vessel CAD involving the proximal LAD } \\
\text { - Low-risk findings on noninvasive testing } \\
\text { - Receiving no or minimal anti-ischemic medical therapy }\end{array}$ & U (4) & $U(5)$ & $A(7)$ \\
\hline
\end{tabular}


TABLE 2. Continued

\begin{tabular}{|c|c|c|c|c|}
\hline \multicolumn{2}{|c|}{ Indication } & \multicolumn{3}{|c|}{ Appropriate Use Score (1-9) } \\
\hline \multicolumn{2}{|r|}{ CCS Angina Class } & Asymptomatic & I or II & III or IV \\
\hline 31. & $\begin{array}{l}\text { - One-vessel CAD involving the proximal LAD } \\
\text { - Low-risk findings on noninvasive testing } \\
\text { - Receiving maximal anti-ischemic medical therapy }\end{array}$ & U (4) & $A(7)$ & $A(8)$ \\
\hline 32. & $\begin{array}{l}\text { - One-vessel CAD involving the proximal LAD } \\
\text { - Intermediate-risk findings on noninvasive testing } \\
\text { - Receiving no or minimal anti-ischemic medical therapy }\end{array}$ & $\mathbf{U}(4)$ & $\mathbf{U}(6)$ & $A(7)$ \\
\hline 33. & $\begin{array}{l}\text { - One-vessel CAD involving the proximal LAD } \\
\text { - Intermediate-risk findings on noninvasive testing } \\
\text { - Receiving maximal anti-ischemic medical therapy }\end{array}$ & U (5) & $A(8)$ & $A(9)$ \\
\hline 34. & $\begin{array}{l}\text { - One-vessel CAD involving the proximal LAD } \\
\text { - High-risk findings on noninvasive testing } \\
\text { - Receiving no or minimal anti-ischemic medical therapy }\end{array}$ & A (7) & $A(8)$ & $A(9)$ \\
\hline 35. & $\begin{array}{l}\text { - One-vessel CAD involving the proximal LAD } \\
\text { - High-risk findings on noninvasive testing } \\
\text { - Receiving maximal anti-ischemic medical therapy }\end{array}$ & $A(7)$ & $A(9)$ & $A(9)$ \\
\hline 36. & $\begin{array}{l}\text { - Two-vessel CAD involving the proximal LAD } \\
\text { - Low-risk findings on noninvasive testing } \\
\text { - Receiving no or minimal anti-ischemic medical therapy }\end{array}$ & $\mathbf{U}(4)$ & $U(6)$ & $A(7)$ \\
\hline 37. & $\begin{array}{l}\text { - Two-vessel CAD involving the proximal LAD } \\
\text { - Low-risk findings on noninvasive testing } \\
\text { - Receiving a course of maximal anti-ischemic medical therapy }\end{array}$ & U (5) & $A(7)$ & $A(8)$ \\
\hline 38. & $\begin{array}{l}\text { - Two-vessel CAD involving the proximal LAD } \\
\text { - Intermediate-risk findings on noninvasive testing } \\
\text { - Receiving no or minimal anti-ischemic medical therapy }\end{array}$ & U (5) & $A(7)$ & $A(8)$ \\
\hline 39. & $\begin{array}{l}\text { - Two-vessel CAD involving the proximal LAD } \\
\text { - Intermediate-risk findings on noninvasive testing } \\
\text { - Receiving a course of maximal anti-ischemic medical therapy }\end{array}$ & $U(6)$ & $A(7)$ & $A(9)$ \\
\hline 40. & $\begin{array}{l}\text { - Two-vessel CAD involving the proximal LAD } \\
\text { - High-risk findings on noninvasive testing } \\
\text { - Receiving no or minimal anti-ischemic medical therapy }\end{array}$ & $A(7)$ & $A(8)$ & $A(9)$ \\
\hline 41. & $\begin{array}{l}\text { - Two-vessel CAD involving the proximal LAD } \\
\text { - High-risk findings on noninvasive testing } \\
\text { - Receiving a course of maximal anti-ischemic medical therapy }\end{array}$ & $A(8)$ & $A(9)$ & $A(9)$ \\
\hline 42. & $\begin{array}{l}\text { - Three-vessel CAD (no left main) } \\
\text { - Low-risk findings on noninvasive testing including normal } \\
\text { LV systolic function } \\
\text { - Receiving no or minimal anti-ischemic medical therapy }\end{array}$ & $U(5)$ & $U(6)$ & $A(7)$ \\
\hline 43. & $\begin{array}{l}\text { - Three-vessel CAD (no left main) } \\
\text { - Low-risk findings on noninvasive testing including normal } \\
\text { LV systolic function } \\
\text { - Receiving a course of maximal anti-ischemic medical therapy }\end{array}$ & U (5) & $A(7)$ & $A(8)$ \\
\hline 44. & $\begin{array}{l}\text { - Three-vessel CAD (no left main) } \\
\text { - Intermediate-risk findings on noninvasive testing } \\
\text { - Receiving no or minimal anti-ischemic medical therapy }\end{array}$ & A (7) & $A(7)$ & $A(8)$ \\
\hline 45. & $\begin{array}{l}\text { - Three-vessel CAD (no left main) } \\
\text { - Intermediate-risk findings on noninvasive testing } \\
\text { - Receiving a course of maximal anti-ischemic medical therapy }\end{array}$ & $A(7)$ & $A(8)$ & $A(9)$ \\
\hline 46. & $\begin{array}{l}\text { - Three-vessel CAD (no left main) } \\
\text { - High-risk findings on noninvasive testing } \\
\text { - Receiving no or minimal anti-ischemic medical therapy }\end{array}$ & $A(7)$ & $A(8)$ & $A(9)$ \\
\hline 47. & $\begin{array}{l}\text { - Three-vessel CAD (no left main) } \\
\text { - High-risk findings on noninvasive testing } \\
\text { - Receiving a course of maximal anti-ischemic medical therapy }\end{array}$ & $A(8)$ & $A(9)$ & $A(9)$ \\
\hline 48. & $\begin{array}{l}\text { - Three-vessel CAD (no left main) } \\
\text { - Abnormal LV systolic function }\end{array}$ & $A(8)$ & $A(9)$ & $A(9)$ \\
\hline 49. & - Left main stenosis & $A(9)$ & $A(9)$ & $A(9)$ \\
\hline
\end{tabular}

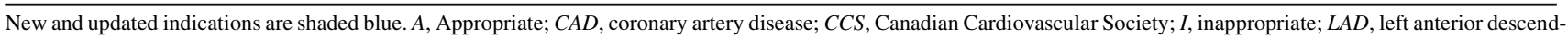
ing coronary artery; $L V$, left ventricular; $L V E F$, left ventricular ejection fraction; $U$, uncertain. *FFR cut point updated from 0.75 to 0.80 to reflect new literature since publication of the original document and to maintain consistency with guidelines. ${ }^{18}$ 
TABLE 3. Patients with prior bypass surgery (without acute coronary syndrome)

\begin{tabular}{|c|c|c|c|c|}
\hline \multicolumn{2}{|c|}{ Indication } & \multicolumn{3}{|c|}{ Appropriate Use Score (1-9) } \\
\hline \multicolumn{2}{|r|}{ CCS Angina Class } & \multirow{2}{*}{$\begin{array}{c}\text { Asymptomatic } \\
\text { I(3) }\end{array}$} & \multirow{2}{*}{\begin{tabular}{|l|} 
I or II \\
$U(4)$
\end{tabular}} & \multirow{2}{*}{$\frac{\text { III or IV }}{\text { U (6) }}$} \\
\hline 50. & $\begin{array}{l}\text { - One or more stenoses in saphenous vein graft(s) } \\
\text { - Low-risk findings on noninvasive testing including normal LV systolic function } \\
\text { - Receiving no or minimal anti-ischemic medical therapy }\end{array}$ & & & \\
\hline 51. & $\begin{array}{l}\text { - One or more stenoses in saphenous vein graft(s) } \\
\text { - Low-risk findings on noninvasive testing including normal LV systolic function } \\
\text { - Receiving a course of maximal anti-ischemic medical therapy }\end{array}$ & U (4) & $U(6)$ & A (7) \\
\hline 52. & $\begin{array}{l}\text { - One or more stenoses in saphenous vein graft(s) } \\
\text { - Intermediate-risk findings on noninvasive testing } \\
\text { - Receiving no or minimal anti-ischemic medical therapy }\end{array}$ & U (4) & $U(6)$ & $A(7)$ \\
\hline 53. & $\begin{array}{l}\text { - One or more stenoses in saphenous vein graft(s) } \\
\text { - Intermediate-risk findings on noninvasive testing } \\
\text { - Receiving a course of maximal anti-ischemic medical therapy }\end{array}$ & U (4) & $A(7)$ & $A(8)$ \\
\hline 54. & $\begin{array}{l}\text { - One or more stenoses in saphenous vein graft(s) } \\
\text { - High-risk findings on noninvasive testing } \\
\text { - Receiving no or minimal anti-ischemic medical therapy }\end{array}$ & $U(6)$ & $A(7)$ & A (7) \\
\hline 55. & $\begin{array}{l}\text { - One or more stenoses in saphenous vein graft(s) } \\
\text { - High-risk findings on noninvasive testing } \\
\text { - Receiving a course of maximal anti-ischemic medical therapy }\end{array}$ & $A(7)$ & $A(8)$ & $A(9)$ \\
\hline 56. & $\begin{array}{l}\text { - One or more lesions in native coronary arteries without bypass grafts } \\
\text { - All bypass grafts patent and without significant disease } \\
\text { - Low-risk findings on noninvasive testing including normal LV systolic function } \\
\text { - Receiving no or minimal anti-ischemic medical therapy }\end{array}$ & Not rated & $I(3)$ & $U(6)$ \\
\hline 57. & $\begin{array}{l}\text { - One or more lesions in native coronary arteries without bypass grafts } \\
\text { - All bypass grafts patent and without significant disease } \\
\text { - Low-risk findings on noninvasive testing including normal LV systolic function } \\
\text { - Receiving a course of maximal anti-ischemic medical therapy }\end{array}$ & I (3) & U (5) & A (7) \\
\hline 58. & $\begin{array}{l}\text { - One or more lesions in native coronary arteries without bypass grafts } \\
\text { - All bypass grafts patent and without significant disease } \\
\text { - Intermediate-risk findings on noninvasive testing } \\
\text { - Receiving no or minimal anti-ischemic medical therapy }\end{array}$ & I (3) & U (5) & $A(7)$ \\
\hline 59. & $\begin{array}{l}\text { - One or more lesions in native coronary arteries without bypass grafts } \\
\text { - All bypass grafts patent and without significant disease } \\
\text { - Intermediate-risk findings on noninvasive testing } \\
\text { - Receiving a course of maximal anti-ischemic medical therapy }\end{array}$ & U (4) & $U(6)$ & $A(8)$ \\
\hline 60. & $\begin{array}{l}\text { - One or more lesions in native coronary arteries without bypass grafts } \\
\text { - All bypass grafts patent and without significant disease } \\
\text { - High-risk findings on noninvasive testing } \\
\text { - Receiving no or minimal anti-ischemic medical therapy }\end{array}$ & $U(6)$ & $A(7)$ & A (8) \\
\hline 61. & $\begin{array}{l}\text { - One or more lesions in native coronary arteries without bypass grafts } \\
\text { - All bypass grafts patent and without significant disease } \\
\text { - High-risk findings on noninvasive testing } \\
\text { - Receiving a course of maximal anti-ischemic medical therapy }\end{array}$ & U (5) & $A(8)$ & $A(9)$ \\
\hline
\end{tabular}

A, Appropriate; $C C S$, Canadian Cardiovascular Society; $I$, inappropriate; $L V$, left ventricular; $U$, uncertain. 
TABLE 4. Method of revascularization: Multivessel CAD, CCS angina greater than or equal to class III, and/or evidence of intermediate- to highrisk findings on noninvasive testing*

\begin{tabular}{|c|c|c|c|}
\hline \multicolumn{2}{|c|}{ Indication } & \multicolumn{2}{|c|}{$\begin{array}{c}\text { Appropriate } \\
\text { Use Score (1-9) }\end{array}$} \\
\hline & & PCI & CABG \\
\hline 62. & - Two-vessel CAD with proximal LAD stenosis & A (7) & $A(8)$ \\
\hline 63. & - Three-vessel CAD with low CAD burden (ie, 3 focal stenoses, low SYNTAX score) & A (7) & A (9) \\
\hline 64. & $\begin{array}{l}\text { - Three-vessel CAD with intermediate to high CAD burden (ie, multiple diffuse lesions, presence of CTO, or } \\
\text { high SYNTAX score) }\end{array}$ & $\mathbf{U}(4)$ & $A(9)$ \\
\hline 65. & - Isolated left main stenosis & $\mathbf{U}(6)$ & A (9) \\
\hline 66. & $\begin{array}{l}\text { - Left main stenosis and additional CAD with low CAD burden (ie, 1- to 2-vessel additional involvement, low } \\
\text { SYNTAX score) }\end{array}$ & $\mathbf{U}(5)$ & $A(9)$ \\
\hline 67. & $\begin{array}{l}\text { - Left main stenosis and additional CAD with intermediate to high CAD burden (ie, 3-vessel involvement, } \\
\text { presence of CTO, or high SYNTAX score) }\end{array}$ & $I(3)$ & $A(9)$ \\
\hline 68. & $\begin{array}{l}\text { - Prior bypass surgery with native 3-vessel disease and failure of multiple bypass grafts } \\
\text { - LIMA remains patent to a native coronary artery } \\
\text { - Depressed LVEF }\end{array}$ & $U(6)$ & A (7) \\
\hline 69. & $\begin{array}{l}\text { - Prior bypass surgery with native 3-vessel disease and failure of multiple bypass grafts } \\
\text { - LIMA was used as a graft but is no longer functional } \\
\text { - Depressed LVEF }\end{array}$ & $A(8)$ & $U(6)$ \\
\hline
\end{tabular}

$\overline{\text { New and updated indications are shaded blue. } A \text {, Appropriate; } C A B G \text {, coronary artery bypass graft; } C A D \text {, coronary artery disease; } C C S \text {, Canadian Cardiovascular Society; } C T O}$ chronic total occlusion; $I$, inappropriate; $L A D$, left anterior descending coronary artery; $L I M A$, left internal mammary artery; $L V E F$, left ventricular ejection fraction; $P C I$, percutaneous coronary intervention; SYNTAX, Synergy Between PCI With TAXUS and Cardiac Surgery; U, uncertain. *The 2009 appropriate use criteria. ${ }^{1}$ separated out diabetes and normal or depressed LVEF for the indications in this table, but they were combined for the focused update because these clinical variables did not affect the ratings.
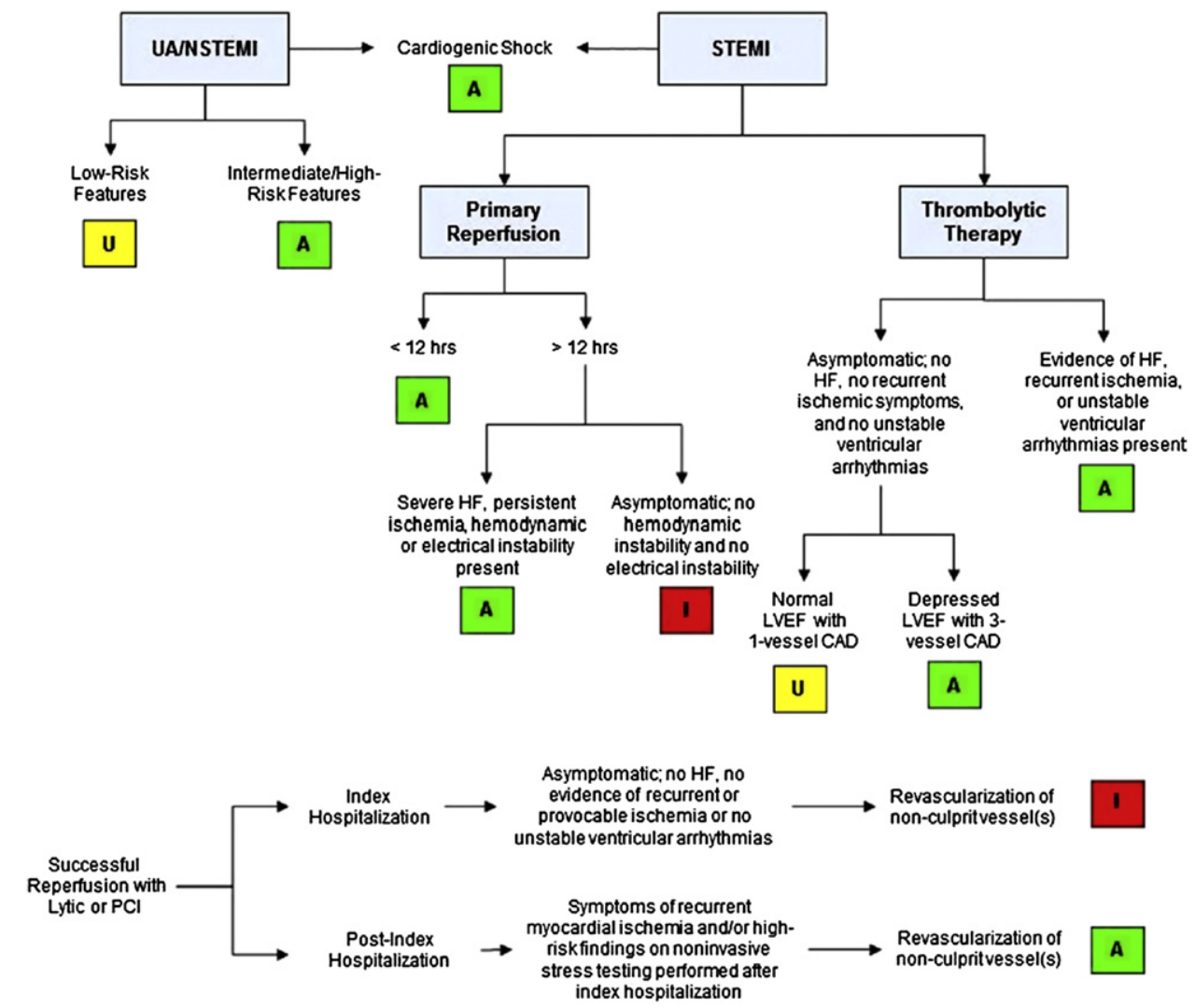

FIGURE 1. Appropriate use ratings for revascularization in acute coronary syndromes.* The fact that the use of coronary revascularization for a particular condition is listed in this figure (appropriate, uncertain, inappropriate) does not preclude the use of other therapeutic modalities that may be equally effective. See the most current ACCF/AHA UA/NSTEMI and STEMI guidelines. ${ }^{16,23} A$, Appropriate; $C A D$, coronary artery disease; $H F$, heart failure; $I$, inappropriate; $L V E F$, left ventricular ejection fraction; $P C I$, percutaneous coronary intervention; STEMI, ST-elevation myocardial infarction; $U$, uncertain; UA/NSTEMI, unstable angina/non-ST-elevation myocardial infarction. 


\begin{tabular}{|c|c|c|c|c|c|c|c|c|c|c|c|}
\hline \multicolumn{6}{|c|}{ Low-Risk Findings on Noninvasive Study } & \multicolumn{6}{|c|}{ Asymptomatic } \\
\hline $\begin{array}{l}\text { Symptoms } \\
\text { Med. Rx }\end{array}$ & & & & & & $\begin{array}{l}\text { Stress Test } \\
\text { Med. Rx }\end{array}$ & & & & & \\
\hline $\begin{array}{l}\text { Class III or IV } \\
\text { Max Rx }\end{array}$ & $\mathbf{U}$ & $\mathbf{A}$ & $\mathbf{A}$ & $\mathbf{A}$ & $\mathbf{A}$ & $\begin{array}{l}\text { High Risk } \\
\text { Max Rx }\end{array}$ & $\mathbf{U}$ & $\mathbf{A}$ & $\mathbf{A}$ & $\mathbf{A}$ & $\mathbf{A}$ \\
\hline $\begin{array}{l}\text { Class Ior II } \\
\text { Max Rx }\end{array}$ & $\mathbf{U}$ & $\mathbf{U}$ & $\mathbf{A}$ & $\mathbf{A}$ & $\mathbf{A}$ & $\begin{array}{l}\text { High Risk } \\
\text { No/min Rx }\end{array}$ & $\mathbf{U}$ & $\mathbf{U}$ & A & $\mathbf{A}$ & A \\
\hline $\begin{array}{l}\text { Asymptomatic } \\
\text { Max } \mathrm{Rx}\end{array}$ & 1 & 1 & $\mathbf{U}$ & $\mathbf{U}$ & $\mathbf{U}$ & $\begin{array}{l}\text { Int. Risk } \\
\text { Max Rx }\end{array}$ & $\mathbf{U}$ & $\mathbf{U}$ & $\mathbf{U}$ & $\mathbf{U}$ & $\mathbf{A}$ \\
\hline $\begin{array}{l}\text { Class III or IV } \\
\text { No/min Rx }\end{array}$ & 1 & $\mathbf{U}$ & A & A & A & $\begin{array}{l}\text { Int. Risk } \\
\text { No/min Rx }\end{array}$ & I & 1 & $\mathbf{U}$ & $\mathbf{U}$ & A \\
\hline $\begin{array}{l}\text { Class Ior II } \\
\text { No/min Rx }\end{array}$ & I & I & $\mathbf{U}$ & $\mathbf{U}$ & $\mathbf{U}$ & $\begin{array}{l}\text { Low Risk } \\
\text { Max Rx }\end{array}$ & I & I & $\mathbf{U}$ & $\mathbf{U}$ & $\mathbf{U}$ \\
\hline $\begin{array}{l}\text { Asymptomatic } \\
\text { No/min Rx }\end{array}$ & 1 & I & $\mathbf{U}$ & $\mathbf{U}$ & $\mathbf{U}$ & $\begin{array}{l}\text { Low Risk } \\
\text { No/min Rx }\end{array}$ & 1 & 1 & $\mathbf{U}$ & $\mathbf{U}$ & $\mathbf{U}$ \\
\hline $\begin{array}{l}\text { Coronary } \\
\text { Anatomy }\end{array}$ & $\begin{array}{c}\text { CTO of } \\
1-\sqrt{2}: \text { no } \\
\text { other } \\
\text { disease }\end{array}$ & $\begin{array}{l}1-2-\sqrt{ } \\
\text { disease; } \\
\text { no prox. } \\
\text { LAD }\end{array}$ & $\begin{array}{c}1-\sqrt{2} \\
\text { disease } \\
\text { of prox. } \\
\text { LAD }\end{array}$ & 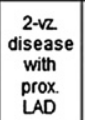 & $\begin{array}{c}3-\sqrt{2} \\
\text { disease; } \\
\text { no left } \\
\text { main }\end{array}$ & $\begin{array}{l}\text { Coronary } \\
\text { Anatomy }\end{array}$ & $\begin{array}{l}\text { CTO of } \\
1-\mathrm{V}: \text { no } \\
\text { other } \\
\text { disease }\end{array}$ & $\begin{array}{c}1-2-\sqrt{2} \\
\text { disease; } \\
\text { no prox. } \\
\text { LAD }\end{array}$ & $\begin{array}{c}1-\sqrt{2} \\
\text { disease } \\
\text { of prox. } \\
\text { LAD }\end{array}$ & 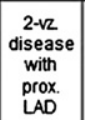 & $\begin{array}{c}3-\sqrt{2} \\
\text { disease: } \\
\text { no left } \\
\text { main }\end{array}$ \\
\hline
\end{tabular}

FIGURE 2. Appropriate use ratings by low-risk findings on noninvasive imaging study and asymptomatic (patients without prior bypass surgery). A, Appropriate; CTO, chronic total occlusion; I, inappropriate; Int., intermediate; Max, maximum; min, minimal; Med., medical; prox. LAD, proximal left anterior descending artery; $R x$, treatment; $U$, uncertain; $v z$. , vessel.

\begin{tabular}{|c|c|c|c|c|c|c|c|c|c|c|c|}
\hline \multicolumn{6}{|c|}{ Intermediate Risk Findings on Noninvasive Study } & \multicolumn{6}{|c|}{ CCS Class I or II Angina } \\
\hline $\begin{array}{l}\text { Symptoms } \\
\text { Med. Rx }\end{array}$ & & & & & & $\begin{array}{l}\text { Stress Test } \\
\text { Med. Rx }\end{array}$ & & & & & \\
\hline $\begin{array}{l}\text { Class II or } N \\
\operatorname{Max} R x\end{array}$ & A & A & A & A & A & $\begin{array}{l}\text { High Risk } \\
\operatorname{Max} R x\end{array}$ & A & A & A & A & A \\
\hline $\begin{array}{l}\text { Class I orll } \\
\operatorname{Max} R x\end{array}$ & $\mathbf{U}$ & A & A & A & A & $\begin{array}{l}\text { High Risk } \\
\text { No/min } R x\end{array}$ & $\mathbf{U}$ & A & A & A & A \\
\hline $\begin{array}{c}\text { Asymptomatic } \\
\operatorname{Max} R x\end{array}$ & $\mathbf{U}$ & $\mathbf{U}$ & $\mathbf{U}$ & $\mathbf{U}$ & A & $\begin{array}{l}\text { Int. Risk } \\
\text { Max Rx }\end{array}$ & $\mathbf{U}$ & A & A & A & A \\
\hline $\begin{array}{l}\text { Class If or } N \\
\mathrm{No} / \min \mathrm{Rx}\end{array}$ & $\mathbf{U}$ & $\mathbf{U}$ & A & A & A & $\begin{array}{l}\text { Int. Risk } \\
\text { No/min Rx }\end{array}$ & $\mathbf{U}$ & $\mathbf{U}$ & $\mathbf{U}$ & A & A \\
\hline $\begin{array}{l}\text { Class I or I } \\
\text { No/min } R x\end{array}$ & $\mathbf{U}$ & $\mathbf{U}$ & $\mathbf{U}$ & A & A & $\begin{array}{l}\text { Low Risk } \\
\text { Max Rx }\end{array}$ & $\mathbf{U}$ & $\mathbf{U}$ & A & A & A \\
\hline $\begin{array}{l}\text { Asymptomatic } \\
\mathrm{No} / \mathrm{min} \mathrm{Rx}\end{array}$ & I & I & $\mathbf{U}$ & $\mathbf{U}$ & A & $\begin{array}{l}\text { Low Risk } \\
\text { No/min Rx }\end{array}$ & 1 & 1 & $\mathbf{U}$ & $\mathbf{U}$ & $\mathbf{U}$ \\
\hline $\begin{array}{l}\text { Coronary } \\
\text { Anatomy }\end{array}$ & $\begin{array}{c}\text { CTO of 1 } \\
\text { vz:; no } \\
\text { other } \\
\text { disease }\end{array}$ & $\begin{array}{c}\text { 1-2 vz. } \\
\text { disease; } \\
\text { no Prox. } \\
\text { LAD }\end{array}$ & $\begin{array}{l}1 \mathrm{vz} . \\
\text { disease } \\
\text { of Prox. } \\
\text { LAD }\end{array}$ & $\begin{array}{c}2 \text { vz. } \\
\text { disease } \\
\text { with } \\
\text { Prox. } \\
\text { LAD }\end{array}$ & $\begin{array}{c}3 \text { vz. } \\
\text { disease; } \\
\text { no Left } \\
\text { Main }\end{array}$ & $\begin{array}{l}\text { Coronary } \\
\text { Anatomy }\end{array}$ & $\begin{array}{c}\text { CTO of 1 } \\
\text { vz.; no } \\
\text { other } \\
\text { disease }\end{array}$ & $\begin{array}{c}1-2 \mathrm{vz} . \\
\text { disease; } \\
\text { no Prox. } \\
\text { LAD }\end{array}$ & $\begin{array}{c}1 \mathrm{vz} . \\
\text { disease } \\
\text { of Prox. } \\
\text { LAD }\end{array}$ & $\begin{array}{l}2 \text { vz. } \\
\text { disease } \\
\text { with } \\
\text { Prox. } \\
\text { LAD }\end{array}$ & $\begin{array}{c}3 \text { vz. } \\
\text { disease: } \\
\text { no Left } \\
\text { Main }\end{array}$ \\
\hline
\end{tabular}

FIGURE 3. Appropriate use ratings by intermediate-risk findings on noninvasive imaging study and CCS class I or II angina (patients without prior bypass surgery). A, Appropriate; CCS, Canadian Cardiovascular Society; CTO, chronic total occlusion; I, inappropriate; Int., intermediate; Max, maximum; min, minimal; Med., medical; prox. $L A D$, proximal left anterior descending artery; $R x$, treatment; $U$, uncertain; $v z$., vessel. 


\begin{tabular}{|c|c|c|c|c|c|c|c|c|c|c|c|}
\hline \multicolumn{6}{|c|}{ High-Risk Findings on Noninvasive Study } & \multicolumn{6}{|c|}{ CCS Class III or IV Angina } \\
\hline $\begin{array}{c}\text { Symptoms } \\
\text { Med. Rx }\end{array}$ & & & & & & $\begin{array}{l}\text { Stress Test } \\
\text { Med. Rx }\end{array}$ & & & & & \\
\hline $\begin{array}{l}\text { Class II or N } \\
\operatorname{Max} R x\end{array}$ & A & A & A & A & A & $\begin{array}{l}\text { High Risk } \\
\text { Max Rx }\end{array}$ & A & A & A & A & A \\
\hline $\begin{array}{l}\text { Class I orl } \\
\operatorname{Max} \mathrm{Rx}\end{array}$ & A & A & A & A & A & $\begin{array}{l}\text { High Risk } \\
\text { Nolmin } R x\end{array}$ & A & A & A & A & A \\
\hline $\begin{array}{c}\text { Asymptomatic } \\
\operatorname{Max} \mathbb{R x}\end{array}$ & U & A & A & A & A & $\begin{array}{l}\text { hat. Risk } \\
\operatorname{Max} R x\end{array}$ & A & A & A & A & A \\
\hline $\begin{array}{l}\text { Class u or N } \\
\text { No/min } R x\end{array}$ & A & A & A & A & A & $\begin{array}{c}\text { Int. Risk } \\
\text { No/min } \mathrm{Bx}\end{array}$ & U & U & A & A & A \\
\hline $\begin{array}{l}\text { Class Ior! } \\
\text { Nolmin Rx }\end{array}$ & U & A & A & A & A & $\begin{array}{l}\text { Low Risk } \\
\operatorname{Max} R x\end{array}$ & U & A & A & A & A \\
\hline $\begin{array}{l}\text { Asymptomatic } \\
\text { Nolmin Rx }\end{array}$ & U & $\mathbf{U}$ & A & A & A & $\begin{array}{l}\text { Low Risk } \\
\text { Nolmin Rx }\end{array}$ & $\mathbf{I}$ & U & A & A & A \\
\hline $\begin{array}{l}\text { Coronary } \\
\text { Anatomy }\end{array}$ & $\begin{array}{c}\text { cro of } \\
\text { 1-vzz;no } \\
\text { other } \\
\text { disease }\end{array}$ & $\begin{array}{l}\text { 1-2-vz. } \\
\text { disease: } \\
\text { no prox. } \\
\text { LaD }\end{array}$ & $\begin{array}{l}\text { 1-vz. } \\
\text { disezsese } \\
\text { of prox. } \\
\text { LAD }\end{array}$ & $\begin{array}{c}\text { 2-vz. } \\
\text { disease } \\
\text { whth prox } \\
\text { LAD }\end{array}$ & $\begin{array}{l}\text { 3-vzz. } \\
\text { disease: } \\
\text { no left } \\
\text { main }\end{array}$ & $\begin{array}{l}\text { Coronary } \\
\text { Anatomy }\end{array}$ & $\begin{array}{l}\text { cro of } \\
\text { 1-vz:; no } \\
\text { other } \\
\text { disease }\end{array}$ & $\begin{array}{l}\text { 1-2-vz. } \\
\text { disease: } \\
\text { no prox } \\
\text { LaD }\end{array}$ & $\begin{array}{l}\text { 1-vz. } \\
\text { disease } \\
\text { of prox. } \\
\text { LAD }\end{array}$ & $\begin{array}{c}2-v z . \\
\text { disease } \\
\text { with prax } \\
\text { LAD }\end{array}$ & $\begin{array}{c}\text { 3-vz. } \\
\text { disease: } \\
\text { no left } \\
\text { main }\end{array}$ \\
\hline
\end{tabular}

FIGURE 4. Appropriate use ratings by high-risk findings on noninvasive imaging study and CCS class III or IV angina (patients without prior bypass surgery). A, Appropriate; CCS, Canadian Cardiovascular Society; CTO, chronic total occlusion; I, inappropriate; Int., intermediate; Max, maximum; $\min$, minimal; Med., medical; prox. $L A D$, proximal left anterior descending artery; $R x$, treatment; $U$, uncertain; $v z$., vessel.

\begin{tabular}{|c|c|c|}
\cline { 2 - 3 } \multicolumn{1}{c|}{} & CABG & PCI \\
\hline Two-vessel CAD with proximal LAD stenosis & A & A \\
\hline $\begin{array}{c}\text { Three-vessel CAD with low CAD burden (i.e., three } \\
\text { focal stenosis, low SYNTAX score) }\end{array}$ & A & A \\
\hline $\begin{array}{c}\text { Three-vessel CAD with intermediate to high CAD burden (i.e., } \\
\text { multiple diffuse lesions, presence of CTO, or high SYNTAX score) }\end{array}$ & A & U \\
\hline $\begin{array}{c}\text { Isolated left main stenosis } \\
\text { Left main stenosis and additional CAD with low CAD burden (i.e., } \\
\text { one two vessel additional involvement, low SYNTAX score) }\end{array}$ & A & U \\
\hline $\begin{array}{c}\text { Left main stenosis and additional CAD with intermediate to } \\
\text { high CAD burden (i.e., three vessel involvement, } \\
\text { presence of CTO, or high SYNTAX score) }\end{array}$ & A & I \\
\hline
\end{tabular}

FIGURE 5. Method of revascularization of multivessel coronary artery disease. $A$, Appropriate; $C A B G$, coronary artery bypass grafting; $C A D$, coronary artery disease; CTO, chronic total occlusion; I, inappropriate; LAD, left anterior descending artery; PCI, percutaneous coronary intervention; SYNTAX, Synergy Between PCI With TAXUS and Cardiac Surgery; $U$, uncertain. 


\section{RATING REVASCULARIZATION METHODS Mode of Revascularization (Indications 62 to 69)}

Recognizing that variability in revascularization methods is often based upon patient factors and local practice patterns, the majority of indications are not intended to distinguish between the specific modes of revascularization (eg, PCI vs CABG). However, the writing group recognized that among patients with extensive or complex atherosclerosis, the mode of revascularization is also of interest when revascularization is deemed appropriate. Therefore, Table 4 presents clinical scenarios where the technical panelists were asked to consider the appropriate use of PCI and CABG as the revascularization method independently of each other (such that each modality would receive separate scores based on each specific clinical indication). These ratings are not intended to be a competitive ranking of PCI versus CABG, or to prioritize a specific approach when both are rated to have the same level of appropriateness.

Many of the known clinical factors that increase the risk of revascularization are shared between $\mathrm{CABG}$ and percutaneous methods. In the original AUC for revascularization, clinical scenarios were developed that included diabetes and LV function to stratify patients, but when rated, these features did not result in different ratings and thus were not used in this focused update. However, in an attempt to further stratify patients, the SYNTAX score is used in some of the new clinical scenarios.

The clinical scenarios below specifically apply to patients with multivessel CAD. It is assumed for these clinical scenarios that all patients have unacceptable levels of symptoms despite appropriate medical therapy and evidence of intermediate- to high-risk findings on noninvasive testing. In other words, the technical panel assumed that revascularization is appropriate and focused on rating the merit of the different modes with the intent of complete coronary revascularization for each indication.

In addition, it is assumed that no unusual extenuating circumstances exist (inability to comply with antiplatelet agents, patient is do not resuscitate status, patient preference strongly favoring 1 therapy or comorbidities likely to markedly increase procedural risk substantially). As such, the technical panel rated the appropriateness of PCI and CABG based on the information in the indication alone, assuming other variables are not present that would impact the decision.

\section{DISCUSSION}

The ultimate objective of AUC is to improve patient care and health outcomes. The ACCF and its collaborators believe that careful blending of a broad range of clinical experiences and available evidence-based information will help guide a more efficient and equitable allocation of healthcare resources in cardiovascular revascularization. This approach is not intended to diminish the acknowledged difficulty or uncertainty of clinical decision making. Appropriate use criteria are not substitutes for sound clinical judgment and practice experience. It is acknowledged that some patients seen in clinical practice may not be represented in the AUC or have extenuating features when compared with the clinical scenarios presented.

Since the publication of the original coronary revascularization AUC, there has been substantial national focus on the variability and appropriateness of coronary revascularization. The 2009 AUC specifically for coronary revascularization by PCI has been mapped to the National Cardiovascular Data, Registry (NCDR) CathPCI registry data, and each institution's benchmarked results are now provided to member facilities in quarterly reports as a test quality metric. This initial assessment of PCI appropriateness within the NCDR data was also published by Chan and colleagues. ${ }^{19}$ Hospitals and operators are encouraged to review their specific reports as part of a quality improvement program to ensure data accuracy and increase the use of appropriate revascularization. Additionally, the SYNTAX trial, which was not formally published until 2009, was anticipated to possibly have an impact on the AUC. Despite calls for earlier updates of specific clinical scenarios, such as the isolated left main coronary artery revascularization, the writing group awaited the peerreviewed publication of both the original trial data and the intermediate-term follow-up.

This focused update highlights 2 specific areas that were felt to require reconsideration: (1) specific indications that represent gaps identified when mapping the 2009 AUC to the CathPCI registry; and (2) re-evaluation of the indications for the treatment of multivessel CAD with symptoms by method (PCI and CABG) of revascularization as a result of data from the SYNTAX trial.

\section{New Clinical Scenarios to Address Gaps}

The 2009 AUC document only had 1 clinical scenario for UA/NSTEMI and high-risk features, which was graded as appropriate. The ratings for these new clinical scenarios (Indications 9 and 10) focus on patients with UA/NSTEMI and low- or intermediate-risk features as determined by the TIMI score. Revascularization in such patients with a lowrisk score was graded as uncertain, meaning that revascularization may be reasonable, with the caveat that there is limited data on clinical benefit. For patients with an intermediate-risk score, revascularization was rated appropriate as it was for patients at high risk (Figure 1).

In the 2009 AUC document, the clinical scenario of an asymptomatic patient without prior bypass surgery and with 1- or 2-vessel disease not involving the proximal LAD in whom no noninvasive testing had been performed was not evaluated because this clinical scenario was felt to be uncommon. However, for future mapping of the AUC to the CathPCI registry, the appropriateness of this clinical scenario was graded in this focused update and 
determined to be inappropriate. This did not affect the appearance of Figures 2, 3, and 4 below because they include indications that were not updated.

\section{PCI and CABG in Patients With Multivessel CAD}

In this group of ratings, it is assumed that revascularization is appropriate, and the technical panel rated the appropriateness of the mode of revascularization independently for CABG and PCI (Figure 5). The writing group and technical panel felt some quantification of CAD burden, either by description or SYNTAX score, could be helpful to clinicians. CABG was rated as appropriate in all of the new clinical scenarios developed, whereas PCI was rated as appropriate only in patients with 2-vessel CAD with involvement of the proximal LAD and in patients with 3-vessel disease with a low CAD burden. PCI for 3-vessel disease with a high CAD burden, however, was rated as uncertain. PCI for isolated left main stenosis is now graded as uncertain, as are scenarios with 3-vessel CAD with intermediate to high CAD burden and left main stenosis and additional CAD with low CAD burden. PCI is considered inappropriate for left main stenosis and additional CAD with intermediate to high CAD burden.

\section{Clinical Judgment and Understanding the AUC Ratings}

Although the appropriate use ratings reflect a general assessment of when revascularization may or may not be useful for specific patient populations, physicians and other stakeholders should continue to acknowledge the pivotal role of clinical judgment in determining whether revascularization is indicated for an individual patient. For example, the rating of a revascularization indication as inappropriate or uncertain should not preclude a provider from performing revascularization procedures when there are patient- and condition-specific data to support that decision. Indeed, this may reflect optimal clinical care, if supported by mitigating patient characteristics. Likewise, uncertain indications require individual physician judgment and understanding of the patient to better determine the usefulness of revascularization for a particular clinical scenario. The ranking of uncertain (4 to 6) should not be viewed as excluding the use of revascularization for such patients. Finally, there may be clinical scenarios in which the use of coronary revascularization for an indication considered to be appropriate does not always represent reasonable practice, such that the benefit of the procedure does not outweigh the risks. Accordingly, the AUC are intended to evaluate overall patterns of care regarding revascularization rather than adjudicating specific cases. In situations where there is substantial variation between the appropriate use rating and what the clinician believes is the best recommendation for the patient, further considerations or actions such as a second opinion may be appropriate. It is not anticipated that all physicians or facilities will have $100 \%$ of their revascularization procedures deemed appropriate. However, related to the overall patterns of care, if the national average of appropriate procedure ratings is $80 \%$, eg, and a physician or facility has only a $40 \%$ rate of appropriate procedures, further examination of the patterns of care may be warranted and helpful.

\section{Stable Ischemic Heart Disease With Prior CABG}

The writing group did not feel the focused update needed to address any clinical scenarios in patients with stable ischemic heart disease and prior CABG. These indications from the prior document show a pattern similar to that seen in patients without prior CABG; the presence of high-risk findings on noninvasive testing, higher severity of symptoms, or an increasing burden of disease in either the bypass grafts or native coronaries increased the likelihood of an appropriate rating. The only inappropriate ratings in patients with prior $\mathrm{CABG}$ were noted in patients receiving no or minimal anti-ischemic therapy or having low-risk findings on noninvasive testing. More uncertain ratings occurred in this group of patients, reflecting their higher complexity, higher risk, and the limited availability of published evidence regarding management outcome.

\section{Application of Criteria}

There are many potential applications for the AUC. Clinicians can use the ratings for decision support or as an educational tool when considering the need for revascularization. Moreover, these criteria can be used to facilitate discussion with patients and/or referring physicians about the need for revascularization. Facilities and payers may choose to use these criteria either prospectively in the design of protocols or pre-authorization procedures, or retrospectively for quality reports. It is hoped that payers would use these criteria to ensure that their members receive necessary, beneficial, and cost-effective cardiovascular care, rather than for other purposes.

It is expected that services performed for appropriate indications will receive reimbursement. In contrast, services performed for inappropriate indications may require additional documentation to justify payment because of the unique circumstances or the clinical profile that may exist in such a patient. This additional documentation should not be required for uncertain indications. It is critical to emphasize that the writing group, technical panel, AUC Task Force, and clinical community do not believe an uncertain rating justifies denial of reimbursement for revascularization. Rather, uncertain ratings are those in which the available data vary and many other factors exist that may affect the decision to perform or not perform revascularization. The opinions of the technical panel often varied for these indications, reflecting that additional research is needed. Indications with high clinical volume that are rated as uncertain identify important areas for further research. The AUC 
writing group and technical panel favor the collaborative interaction of cardiac surgeons and interventional cardiologists Heart Team approach regarding revascularization decisions in complex patients or coronary anatomy.

When evaluating physician or facility performance, AUC should be used in conjunction with efforts that lead to quality improvement. Prospective pre-authorization procedures, if put in place, are most effective once a retrospective review has identified a pattern of potential inappropriate use. Because these criteria are based on current scientific evidence and the deliberations of the technical panel, they should be used prospectively to generate future discussions about reimbursement, but should not be applied retrospectively to cases completed before issuance of this report or documentation of centers/providers performing an unexpectedly high proportion of inappropriate cases as compared with their peers.

The writing group recognizes that these criteria will be evaluated during routine clinical care. To that end, specific data fields such as symptom status, presence or absence of acute coronary syndrome, history of bypass surgery, extent of ischemia on noninvasive imaging, CAD burden, and degree of antianginal therapy are anticipated to provide sufficient detail to determine individual appropriate use ratings. Because a reasonable and tolerated dose of antianginal therapy may vary significantly among different patients, the writing group continues to recommend the use of 2 classes of antianginal therapies as a minimum standard for medical therapy. The writing group also recognizes all data (eg, visual assessment of stenosis severity, interpretation of noninvasive imaging, symptom severity) collected to assess appropriate use relies on its content accurately reflecting actual patient characteristics. Any current variability in these data points need to be addressed before accurate determination of appropriate use can be provided.

The primary objective of this report is to provide guidance regarding the suitability of coronary revascularization for diverse clinical scenarios. As with previous AUC documents, consensus among the technical panel members was desirable, but an attempt to achieve complete agreement within this diverse panel would have been artificial and was not the goal of the process. Two rounds of ratings with substantial discussion among the technical panel members between the ratings did lead to some consensus among panelists. However, further attempts to drive consensus would have diluted true differences in opinion among panelists and, therefore, was not undertaken. Moreover, remarkable concordance between the appropriateness ratings from the original criteria and 85 cardiologists not participating in the process, and blinded to the initial results, has been documented. ${ }^{20}$

Future research analyzing patient outcomes for indications rated as appropriate will help ensure the equitable and efficient allocation of resources for coronary revascularization. Review of appropriateness patterns may also improve understanding of regional variations in the use of revascularization as highlighted in the Dartmouth Atlas Project. ${ }^{21}$ Further exploration of the indications rated as uncertain will help generate the information required to further define the appropriate use of coronary revascularization. Additionally, the criteria will need to be updated with the publication of ongoing trials in coronary revascularization and new clinical practice guidelines. For additional information and discussion of the literature, please see the ACCF/AHA PCI and CABG guidelines. ${ }^{12,13}$

In conclusion, this document represents the current understanding of the clinical benefit of coronary revascularization with respect to health outcomes and survival. It is intended to provide a practical guide to clinicians and patients when considering revascularization. As with other AUC, the results of some of these ratings will require research and further evaluation to provide the greatest information and benefit to clinical decision making.

\section{APPENDIX A: ADDITIONAL CORONARY REVASCULARIZATION DEFINITIONS Angina/Chest Pain Classification}

Angina is a syndrome typically noted to include discomfort in the chest, jaw, shoulder, back, or arm that is aggravated by exertion or emotional stress and relieved by nitroglycerin. The quality of the discomfort, provoking factors, and relieving factors are used to define typical, atypical, and noncardiac chest pain. Atypical angina is generally defined by 2 of the above 3 characteristics, and noncardiac chest pain is generally defined as chest pain that meets 1 or none of the above criteria. These definitions are presented below.

\section{Clinical Classification of Chest Pain ${ }^{22}$ :}

- Typical Angina (Definite): Defined as (1) substernal chest pain or discomfort that is (2) provoked by exertion or emotional stress and (3) relieved by rest and/or nitroglycerin.

- Atypical Angina (Probable): Chest pain or discomfort that lacks 1 of the characteristics of definite or typical angina.

- Nonanginal Chest Pain: Chest pain or discomfort that meets 1 or none of the typical angina characteristics.

The writing group assumes that noninvasive assessments of coronary anatomy (ie, cardiac computed tomography, cardiac magnetic resonance angiography) provide anatomic information that is potentially similar to x-ray angiography. However, these modalities do not currently provide information on ischemic burden and are not assumed to be present in the clinical scenarios.

\section{Invasive Methods of Determining Hemodynamic Significance}

The writing group recognizes that not all patients referred for revascularization will have previous noninvasive testing. 
TABLE A2. Noninvasive risk stratification

High-risk ( $>3 \%$ annual mortality rate)

1. Severe resting left ventricular dysfunction $(\mathrm{LVEF}<35 \%)$

2. High-risk treadmill score (score $\leq-11$ )

3. Severe exercise left ventricular dysfunction (exercise LVEF $<35 \%$ )

4. Stress-induced large perfusion defect (particularly if anterior)

5. Stress-induced multiple perfusion defects of moderate size

6. Large, fixed perfusion defect with LV dilation or increased lung uptake (thallium-201)

7. Stress-induced moderate perfusion defect with LV dilation or increased lung uptake (thallium-201)

8. Echocardiographic wall motion abnormality (involving $>2$ segments) developing at low dose of dobutamine $(\leq 10 \mathrm{mg} / \mathrm{kg} / \mathrm{min})$ or at a low heart rate $(<120$ beats/min $)$

9. Stress echocardiographic evidence of extensive ischemia

Intermediate-risk ( $1 \%$ to $3 \%$ annual mortality rate)

1. Mild/moderate resting left ventricular dysfunction (LVEF $35 \%$ to $49 \%$ )

2. Intermediate-risk treadmill score (score between -11 and $<5$ )

3. Stress-induced moderate perfusion defect without LV dilation or increased lung intake (thallium-201)

4. Limited stress echocardiographic ischemia with a wall motion abnormality only at higher doses of dobutamine involving less than or equal to 2 segments

Low-risk $(<1 \%$ annual mortality rate)

1. Low-risk treadmill score (score $\geq 5$ )

2. Normal or small myocardial perfusion defect at rest or with stress*

3. Normal stress echocardiographic wall motion or no change of limited resting wall motion abnormalities during stress*

$\overline{L V \text {, Left ventricular; } L V E F \text {, left ventricular ejection fraction. *Although the published }}$ data are limited, patients with these findings will probably not be at low risk in the presence of either a high-risk treadmill score or severe resting left ventricular dysfunction $(\mathrm{LVEF}<35 \%)$. Reprinted with permission from Patel et al. ${ }^{1}$

In fact, there are several situations in which patients may be appropriately referred for coronary angiography based on symptom presentation and a high pretest probability of coronary artery disease. In these settings, there may be situations where angiography shows a coronary narrowing of questionable hemodynamic importance in a patient with symptoms that can be related to myocardial ischemia. In such patients, the use of additional invasive measurements (such as fractional flow reserve or intravascular ultrasound) at the time of diagnostic angiography may be very helpful in further defining the need for revascularization and substituted for stress test findings (Table A2).

\section{APPENDIX B: ADDITIONAL METHODS}

See the earlier Methods section of the report for a description of technical panel selection, indication development, scope of indications, and rating process.

\section{Relationships With Industry and Other Entities}

The American College of Cardiology Foundation and its partnering organizations rigorously avoid any actual, perceived, or potential conflicts of interest that might arise as a result of an outside relationship or personal interest of a member of the technical panel. Specifically, all panelists are asked to provide disclosure statements of all relationships that might be perceived as real or potential conflicts of interest. These statements were reviewed by the AUC Task Force, discussed with all members of the technical panel at the face-to-face meeting, and updated and reviewed as necessary. A table of disclosures by all participants, who are listed in Appendix $\mathrm{C}$, in the Appropriate Use Criteria for Coronary Revascularization can be found in Appendix D. In addition, to ensure complete transparency, complete disclosure informationincluding relationships not pertinent to this document-is available online as a document supplement.

\section{Literature Review}

The technical panel members were asked to refer to the relevant guidelines for a summary of the relevant literature, guideline recommendation tables, and reference lists provided for each indication table when completing their ratings (Online Appendix).

\section{APPENDIX C: ACCF/SCAI/STS/AATS/AHA/ASNC/ HFSA/SCCT 2012 APPROPRIATE USE CRITERIA FOR CORONARY REVASCULARIZATION FOCUSED UPDATE PARTICIPANTS}

Coronary Revascularization Writing Group

Manesh R. Patel, MD, FACC-Chair, Appropriate Use Criteria for Coronary Revascularization Writing GroupAssistant Professor of Medicine, Division of Cardiology, Assistant Director, Cardiac Catheterization Lab, Duke University Medical Center, Durham, NC

Gregory J. Dehmer, MD, FACC, FACP, FSCAI, FAHAPast President, Society for Cardiovascular Angiography and Interventions; Professor of Medicine, Texas A\&M School of Medicine; and Director, Cardiology Division, Scott \& White Clinic, Temple, TX

John W. Hirshfeld, MD, FACC_Professor of Medicine, Hospital of The University of Pennsylvania, Department of Medicine, Cardiovascular Medicine Division, Philadelphia, PA

Peter K. Smith, MD, FACC-Professor and Chief, Thoracic Surgery, Duke University, Durham, NC

John A. Spertus, MD, MPH, FACC—Professor, UMKC School of Medicine, Director of CV Education and Outcomes Research, MidAmerica Heart Institute of St. Luke's Hospital, Kansas City, MO

\section{Coronary Revascularization Technical Panel}

Frederick A. Masoudi, MD, MSPH, FACC, FAHA-Moderator for the Technical Panel-Associate Professor of Medicine (Cardiology), University of Colorado Denver, Aurora, CO

Ralph G. Brindis, MD, MPH, FACC, FSCAI*-Methodology Liaison for the Technical Panel-Regional Senior Advisor for Cardiovascular Disease, Northern California Kaiser Permanente; Clinical Professor of Medicine,

\footnotetext{
* Participated in the 2009 Appropriate Use Criteria for Coronary Revascularization only.
} 
University of California at San Francisco; Chief Medical Officer and Chairman, NCDR Management Board, American College of Cardiology Foundation, Washington, DC

Gregory J. Dehmer, MD, FACC, FACP, FSCAI, FAHAWriting Group Liaison for the Technical Panel-Past President, Society for Cardiovascular Angiography and Interventions, Professor of Medicine, Texas A\&M School of Medicine; and Director, Cardiology Division, Scott \& White Clinic, Temple, TX

Manesh R. Patel, MD, FACC-Writing Group Liaison for the Technical Panel-Assistant Professor of Medicine, Division of Cardiology, Duke University Medical Center, Durham, NC

Peter K. Smith, MD, FACC - Writing Group Liaison for the Technical Panel-Professor and Division Chief, Cardiothoracic Surgery, Duke University, Durham, NC

Karen J. Beckman, MD, FACC*-Professor of Medicine, University of Oklahoma Health Science Center, Cardiac Arrhythmia Research Institute, Oklahoma City, OK

Charles E. Chambers, MD, FACC, FSCAI-Professor of Medicine and Radiology, Penn State University, Hershey Medical Center, Hershey, PA

T. Bruce Ferguson Jr., MD, FACC, FAHA-Chairman, Department of Cardiovascular Sciences, East Carolina Heart Institute, Greenville, NC

Mario J. Garcia, MD, FACC-Professor of Medicine, Chief, Division of Cardiology Montefiore Medical Center and Albert Einstein College of Medicine, Bronx, NY

Frederick L. Grover, MD, FACC - Professor and Chair, Department of Surgery, University of Colorado School of Medicine, Denver Veterans Affairs Medical Center, Denver, CO

David R. Holmes Jr., MD, FACC, FSCAI—Professor of Medicine, Mayo Clinic, Rochester, MN

Lloyd W. Klein, MD, FACC, FSCAI, FAHA-Advocate Illinois Masonic Medical Center, Chicago, IL

Marian C. Limacher, MD, FACC, FACP, FAHA—Senior Associate Dean for Faculty Affairs and Professional Development, AHA Endowed Professor of Cardiovascular Research, University of Florida College of Medicine, Gainesville, FL

Michael J. Mack, MD, FACC-Medical Director Cardiovascular Surgery, Baylor Healthcare System, Dallas, TX

David J. Malenka, MD, FACC, FAHA-Professor of Medicine, Dartmouth Hitchcock Medical Center, Lebanon, $\mathrm{NH}$

Myung H. Park, MD, FACC-Associate \& Professor of Medicine and Director, Pulmonary Vascular Diseases Program, University of Maryland School of Medicine, Division of Cardiology, Baltimore, MD

Michael Ragosta III, MD, FACC, FSCAI—Director, Cardiac Catheterization Laboratory, Professor of Medicine, University of Virginia, Charlottesville, VA

James L. Ritchie, MD, FACC, FAHA—Consultant, Seattle Veterans Hospital, Bend, OR

Geoffrey A. Rose, MD, FACC, FASE—Director of Imaging, Sanger Heart \& Vascular Institute, Clinical Professor of
Medicine, University of North Carolina at Chapel Hill, Charlotte, NC

Alan B. Rosenberg, MD—Vice President, Clinical Pharmacy and Medical Policy, WellPoint, Inc., Chicago, IL

Andrea M. Russo, MD, FACC, FHRS $\dagger$-Professor of Medicine, University of Medicine and Dentistry of New Jersey/Robert Wood Johnson Medical School, Director, Cardiac Electrophysiology and Arrhythmia Services, Cooper University Hospital, Camden, NJ

Richard J. Shemin, MD, FACC, FAHA-Professor of Surgery, UCLA David Geffen School of Medicine, Chief, Division of Cardiothoracic Surgery; Executive Vice Chair, Department of Surgery; and Co-Director, Cardiovascular Center, Ronald Reagan UCLA Medical Center, Los Angeles, CA

William S. Weintraub, MD, FACC, FAHA-Chief, Section of Cardiology, Director, Christiana Center for Outcomes Research, Christiana Care Health System, Newark, DE

\section{External Reviewers of the Appropriate Use Criteria Indications*}

Stephan Achenbach, MD, FACC, FESC—Professor of Medicine, Department of Cardiology, University of Giessen, Giessen, Germany

Joseph S. Alpert, MD, FACC, MACP, FAHA—Professor of Medicine and Director of Coronary Care, Cardiac Rehabilitation, and the Chest Pain Unit, University of Arizona Health Network, Tucson, AZ; Editor-in-Chief, The American Journal of Medicine

H. Vernon Anderson, MD, FACC, FAHA-Professor of Medicine, Cardiology Division, University of Texas Health Science Center, Houston, TX

Elliott M. Antman, MD, FACC, FAHA-Professor of Medicine, Cardiovascular Division, Brigham and Women's Hospital, Associate Dean for Clinical/Translational Research, Harvard Medical School, Boston, MA

Lee M. Arcement, MD, MPH, FACC, FCCP-Chief of Cardiology, Chabert Medical Center, Houma, LA; Division Director of Heart Failure Disease Management, Louisiana State University Health Care Services, Baton Rouge, LA

R. Morton Bolman III, MD, FACC-Professor of Surgery, Harvard Medical School, and Chief, Division of Cardiac Surgery, Brigham and Women's Hospital, Boston, MA Javed Butler, MBBS, MPH, FACC, FAHA-Professor of Medicine and Director, Heart Failure Research, Emory University, Atlanta, GA

Jun R. Chiong, MD, MPH, FACC, FCCP-Associate Professor of Medicine Medical Director, Advanced Heart Failure Program Loma Linda University Medical Center, Loma Linda, CA

G. William Dec, MD, FACC, FAHA—Professor of Medicine, Harvard Medical School and Chief, Cardiology Division, Massachusetts General Hospital, Boston, MA

${ }^{\dagger}$ Participated in the 2012 Appropriate Use Criteria for Coronary Revascularization Focused Update only. 
David P. Faxon, MD, FACC_-Vice Chair of Medicine for Strategic Planning, Department of Medicine, Brigham and Women's Hospital, Boston, MA

Raymond J. Gibbons, MD, FACC-Professor of Medicine, Mayo Clinic, Rochester, MN

Robert A. Guyton, MD, FACC-Professor of Surgery and Chief of Cardiothoracic Surgery, Emory University School of Medicine, Atlanta, GA

Alice K. Jacobs, MD, FACC-Professor of Medicine, Boston University School of Medicine; Director, Cardiac Catheterization Laboratories and Interventional Cardiology, Boston Medical Center, Boston, MA

John A. Kern, MD, FACS-Professor of Surgery, CoDirector Heart and Vascular Center, University of Virginia Health System, Charlottesville, VA

Lloyd W. Klein, MD, FACC, FSCAI, FAHA-Professor of Medicine, Rush University Medical Center, Chicago, IL

Michael J. Mack, MD, FACC-Director, Cardiopulmonary Research Science Technology Institute, Baylor Healthcare System, Dallas, TX

L. Brent Mitchell, MD, FACC, FRCPC-Professor and Head, Department of Cardiac Sciences, Calgary Health Region and University of Calgary; Director, Libin Cardiovascular Institute of Alberta, Calgary, AB, Canada

Marc R. Moon, MD, FACC-Joseph C. Bancroft Professor of Surgery, Barnes-Jewish Hospital/Washington University, St. Louis, MO

Douglass A. Morrison, MD, PhD, FACC, FSCAI—Professor of Medicine, Director, Cardiac Catheterization Lab, Yakima Heart Center, Yakima, WA

Reid T. Muller, MD, FACC, FACP—Albany Associates in Cardiology, St. Peter's Hospital, Albany, NY

Sherif F. Nagueh, MD, FACC-Professor of Medicine, Methodist DeBakey Heart and Vascular Center, Houston, TX

Navin C. Nanda, MD, FACC-Distinguished Professor of Medicine and Cardiovascular Disease and Director, Heart Station/Echocardiography Laboratories, University of Alabama at Birmingham, Birmingham, AL

William C. Nugent, MD-Professor and Chief, Cardiothoracic Surgery, Dartmouth-Hitchcock Medical Center, Lebanon, NH

Myung H. Park, MD, FACC-Associate Professor of Medicine and Director, Pulmonary Vascular Diseases Program, University of Maryland School of Medicine, Division of Cardiology, Baltimore, MD

Michael Poon, MD, FACC-Associate Clinical Professor of Medicine, Cabrini Medical Center, New York, NY

John D. Puskas, MD, FACC—Professor of Surgery (Cardiothoracic) and Associate Chief of Cardiothoracic Surgery, Emory University; Chief of Cardiac Surgery, Emory Crawford Long Hospital, Atlanta, GA

J. Scott Rankin, MD—Associate Clinical Professor, Vanderbilt University, Nashville, TN
Rita F. Redberg, MD, MSc, FACC, FAHA-Professor of Medicine, University of California at San Francisco School of Medicine, Division of Cardiology, San Francisco, CA

Michael W. Rich, MD, FACC, FAHA-Professor of Medicine, Cardiovascular Division, Washington University School of Medicine, St. Louis, MO

Craig R. Smith, MD, FACC—Johnson \& Johnson Distinguished Professor and Valentine Mott Professor of Surgery, Chairman, Department of Surgery, College of Physicians \& Surgeons of Columbia University, Columbia University Medical Center, New York Presbyterian Hospital, New York, NY

Barry F. Uretsky, MD, FACC, FSCAI, FAHA-Clinical Professor of Medicine, University of Arkansas for Medical Sciences, Director, Interventional Cardiology, Central Arkansas Veterans Health System, Little Rock, AR

Edward D. Verrier, MD, FACC, FACS, FAHA-K. Alvin \& Shirley Merendino Endowed Professor of Cardiovascular Surgery, Vice Chairman for Clinical Affairs, Department of Surgery, University of Washington, Surgical Director, Joint Council on Thoracic Surgery Education, Seattle, WA

Susan J. Zieman, MD, PhD, FACC-Medical Officer, Geriatrics Branch, Division of Geriatrics and Clinical Gerontology, National Institute on Aging/National Institutes of Health, Bethesda, MD

\section{ACCF Appropriate Use Criteria Task Force}

Michael J. Wolk, MD, MACC-Chair, Task Force, Past President, American College of Cardiology Foundation and Clinical Professor of Medicine, Weill-Cornell Medical School, New York, NY

Steven R. Bailey, MD, FACC, FSCAI, FAHA-Chair, Division of Cardiology, Professor of Medicine and Radiology, Janey Briscoe Distinguished Chair, University of Texas Health Sciences Center, San Antonio, TX

Pamela S. Douglas, MD, MACC, FAHA, FASE—Past President, American College of Cardiology Foundation; Past President American Society of Echocardiography; and Ursula Geller Professor of Research in Cardiovascular Diseases, Duke University Medical Center, Durham, NC

Robert C. Hendel, MD, FACC, FAHA, FASNC-Chair, Appropriate Use Criteria for Radionuclide Imaging Writing Group-Director of Cardiac Imaging and Outpatient Services, Division of Cardiology, Miami University School of Medicine, Miami, FL

Christopher M. Kramer, MD, FACC, FAHA-Professor of Medicine and Radiology and Director, Cardiovascular Imaging Center, University of Virginia Health System, Charlottesville, VA

James K. Min, MD, FACC—Director of Cardiac Imaging Research and Co-Director of Cardiac Imaging, CedarsSinai Heart Institute, Los Angeles, CA

Manesh R. Patel, MD, FACC-Assistant Professor of Medicine, Division of Cardiology, Duke University Medical Center, Durham, NC 
Leslee Shaw, PhD, FACC, FASNC-Professor of Medicine, Emory University School of Medicine, Atlanta, GA

Raymond F. Stainback, MD, FACC, FASE-Medical Director of Noninvasive Cardiac Imaging, Texas Heart Institute at St. Luke's Episcopal Hospital; Clinical Associate
Professor of Medicine, Baylor College of Medicine, Houston, TX

Joseph M. Allen, MA-Director, TRIP (Translating Research Into Practice), American College of Cardiology Foundation, Washington, DC

APPENDIX D. ACCF/SCAI/STS/AATS/AHA/ASNC/HFSA/SCCT 2012 appropriate use criteria for coronary revascularization focused update writing group, technical panel, indication reviewers, * and task force-relationships with industry and other entities (in alphabetical order)

\begin{tabular}{|c|c|c|c|c|c|c|}
\hline Participant & Consultant & Speaker & $\begin{array}{l}\text { Ownership/ } \\
\text { partnership/ } \\
\text { principal }\end{array}$ & Research & $\begin{array}{c}\text { Institutional, } \\
\text { organizational, or } \\
\text { other financial Benefit }\end{array}$ & $\begin{array}{l}\text { Expert } \\
\text { witness }\end{array}$ \\
\hline \multicolumn{7}{|c|}{ Coronary revascularization appropriate use criteria writing group } \\
\hline Manesh R. Patel & None & None & None & None & None & None \\
\hline Gregory J. Dehmer & None & None & None & None & None & None \\
\hline John W. Hirshfeld & $\begin{array}{l}\text { - St. Jude } \\
\text { Medical }\end{array}$ & None & None & None & None & None \\
\hline Peter K. Smith & - Eli Lilly & None & None & None & None & None \\
\hline John A. Spertus & $\begin{array}{l}\text { - St. Jude } \\
\text { Medical }\end{array}$ & None & None & $\begin{array}{l}\text { - } \text { BMS/sanofi-aventis } \\
\text { partnership } \dagger \\
\text { - Eli Lilly } \dagger\end{array}$ & None & None \\
\hline \multicolumn{7}{|c|}{ Coronary revascularization appropriate use criteria technical panel } \\
\hline Frederick A. Masoudi & None & None & None & None & None & None \\
\hline Ralph G. Brindis & None & None & None & None & None & None \\
\hline Gregory J. Dehmer & None & None & None & None & None & None \\
\hline Manesh R. Patel & None & None & None & None & None & None \\
\hline Peter K. Smith & - Eli Lilly & None & None & None & None & None \\
\hline Karen J. Beckman & None & None & None & None & None & None \\
\hline Charles E. Chambers & None & None & None & None & None & None \\
\hline T. Bruce Ferguson & None & None & None & None & None & None \\
\hline Mario J. Garcia & None & None & None & None & None & None \\
\hline Frederick L. Grover & None & None & None & None & None & None \\
\hline David R. Holmes Jr. & None & None & None & None & None & None \\
\hline Lloyd W. Klein & None & None & None & None & None & None \\
\hline Marian C. Limacher & None & None & None & None & None & None \\
\hline Michael J. Mack & None & None & None & None & None & None \\
\hline David J. Malenka & None & None & None & $\begin{array}{l}\text { - St. Jude Medical } \\
\text { Foundation }\end{array}$ & None & None \\
\hline \multicolumn{7}{|l|}{ Myung H. Park } \\
\hline Michael Ragosta III & None & None & None & None & None & None \\
\hline James L. Ritchie & None & None & None & None & None & None \\
\hline Geoffrey A. Rose & None & None & None & None & None & None \\
\hline Alan B. Rosenberg & None & None & - WellPoint, Inc. $\dagger$ & None & - WellPoint, Inc. $\dagger$ & None \\
\hline Andrea M. Russo & $\begin{array}{l}\text { - Medtronic } \\
\text { - Sanofi-Aventis }\end{array}$ & $\begin{array}{l}\text { - Boston Scientific } \\
\text { - Medtronic } \\
\text { - St. Jude Medical }\end{array}$ & None & - Medtronic & None & None \\
\hline Richard J. Shemin & None & None & None & None & None & None \\
\hline William S. Weintraub & None & None & None & None & None & None \\
\hline \multicolumn{7}{|c|}{ Coronary revascularization appropriate use criteria indication reviewers* } \\
\hline Stephan Achenbach & None & None & None & $\begin{array}{l}\text { - Siemens Medical } \\
\text { Solutions }\end{array}$ & None & None \\
\hline Joseph S. Alpert & None & None & None & None & None & None \\
\hline H. Vernon Anderson & None & $\begin{array}{l}\text { - Bristol-Myers Squibb } \\
\text { Pharmaceuticals } \\
\text { - Sanofi-aventis } \\
\text { Pharmaceuticals }\end{array}$ & None & None & None & None \\
\hline
\end{tabular}




\begin{tabular}{|c|c|c|c|c|c|c|}
\hline Participant & Consultant & Speaker & $\begin{array}{l}\text { Ownership/ } \\
\text { partnership/ } \\
\text { principal }\end{array}$ & Research & $\begin{array}{c}\text { Institutional, } \\
\text { organizational, or } \\
\text { other financial Benefit }\end{array}$ & $\begin{array}{l}\text { Expert } \\
\text { witness } \\
\end{array}$ \\
\hline Elliott M. Antman & $\begin{array}{l}\text { - Eli Lilly } \\
\text { - Sanofi-aventis }\end{array}$ & None & None & $\begin{array}{l}\text { - Bristol-Myers Squibb } \\
\text { Pharmaceutical } \\
\text { Research Institute } \\
\text { - Eli Lilly and } \\
\text { Company } \\
\text { - Sanofi-aventis }\end{array}$ & None & None \\
\hline Lee M. Arcement & None & None & None & None & None & None \\
\hline R. Morton Bolman & None & None & None & None & None & None \\
\hline Javed Butler & None & None & None & None & None & None \\
\hline Jun R. Chiong & None & None & None & None & None & None \\
\hline G. William Dec & None & None & None & None & None & None \\
\hline David P. Faxon & None & None & None & None & None & None \\
\hline Raymond J. Gibbons & None & None & None & None & None & None \\
\hline Robert A. Guyton & - Medtronic & None & None & None & None & None \\
\hline Alice K. Jacobs & None & None & None & None & None & None \\
\hline John A. Kern & None & None & None & None & None & None \\
\hline Lloyd W. Klein & None & None & None & None & None & None \\
\hline Michael J. Mack & None & None & None & None & None & None \\
\hline L. Brent Mitchell & - Medtronic & - Medtronic Canada & None & - Medtronic Canada & None & None \\
\hline Marc R. Moon & None & None & None & None & None & None \\
\hline Douglass A. Morrison & None & None & None & None & None & None \\
\hline Reid T. Muller & None & None & None & None & None & None \\
\hline Sherif F. Nagueh & $\begin{array}{l}\text { - GE Healthcare } \\
\text { - St. Jude Medical }\end{array}$ & - Medtronic & None & None & None & None \\
\hline Navin C. Nanda & Philips & None & None & None & None & None \\
\hline William C. Nugent & None & None & None & None & None & None \\
\hline Myung H. Park & None & None & None & None & None & None \\
\hline Michael Poon & None & None & None & None & None & None \\
\hline John D. Puskas & - Medtronic & None & None & $\begin{array}{l}\text { - Medtronic (royalty } \\
\text { income) }\end{array}$ & None & None \\
\hline J. Scott Rankin & None & None & None & None & None & None \\
\hline Rita F. Redberg & None & None & None & None & None & None \\
\hline Michael W. Rich & None & None & None & None & None & None \\
\hline Craig R. Smith & None & None & None & None & None & None \\
\hline Barry F. Uretsky & None & None & None & None & None & None \\
\hline Edward D. Verrier & None & None & None & None & None & None \\
\hline Susan J. Zieman & None & None & None & None & None & None \\
\hline \multicolumn{7}{|c|}{ Appropriate Use Criteria Task Force } \\
\hline Michael J. Wolk & None & None & None & None & None & None \\
\hline Steven R. Bailey & None & None & None & None & None & None \\
\hline Pamela S. Douglas & None & None & None & None & None & None \\
\hline Robert C. Hendel & None & None & None & None & None & None \\
\hline Christopher M. Kramer & None & None & None & None & None & None \\
\hline James K. Min & None & - GE Healthcare & None & None & None & None \\
\hline Manesh R. Patel & None & None & None & None & None & None \\
\hline Leslee Shaw & None & None & None & None & None & None \\
\hline Raymond F. Stainback & None & None & None & None & None & None \\
\hline Joseph M. Allen & None & None & None & None & None & None \\
\hline
\end{tabular}

This table represents the relevant relationships with industry and other entities that were disclosed by participants at the time of participation. It does not necessarily reflect relationships at the time of publication. A person is deemed to have a significant interest in a business if the interest represents ownership of 5\% or more of the voting stock or share of the business entity, or ownership of $\$ 10,000$ or more of the fair market value of the business entity; or if funds received by the person from the business entity exceed $5 \%$ of the person's gross income for the previous year. A relationship is considered to be modest if it is less than significant under the preceding definition. Relationships in this table are modest unless otherwise noted. Names are listed in alphabetical order within each category of review. Participation does not imply endorsement of this document. *Relationships were recorded at the time of review for the 2009 publication. Because the reviewers did not review the focused update, their information was not updated for this document. $\dagger$ Significant relationship. 


\section{STAFF}

American College of Cardiology Foundation

John C. Lewin, MD, Chief Executive Officer

Joseph M. Allen, MA, Director, TRIP (Translating Research Into Practice)

Lea Binder, MA, Senior Research Specialist, Appropriate Use Criteria

Erin A. Barrett, MPS, Senior Specialist, Science and Clinical Policy

\section{References}

1. Patel MR, Dehmer GJ, Hirshfeld JW, Smith PK, Spertus JA. ACCF/SCAI/STS/ AATS/AHA/ASNC 2009 appropriateness criteria for coronary revascularization: a report by the American College of Cardiology Foundation Appropriateness Criteria Task Force, Society for Cardiovascular Angiography and Interventions, Society of Thoracic Surgeons, American Association for Thoracic Surgery, American Heart Association, and the American Society of Nuclear Cardiology. J Am Coll Cardiol. 2009;53:530-53.

2. Kappetein AP, Mohr FW, Feldman TE, et al. Comparison of coronary bypass surgery with drug-eluting stenting for the treatment of left main and/or three-vessel disease: 3-year follow-up of the SYNTAX trial. Eur Heart J. 2011;17:2125-34.

3. Patel MR, Spertus JA, Brindis RG, et al. ACCF proposed method for evaluating the appropriateness of cardiovascular imaging. J Am Coll Cardiol. 2005;46:1606-13.

4. Fitch K, Bernstein SJ, Aguilar MD, et al. The RAND/UCLA Appropriateness Method User's Manual. Arlington, VA: RAND. 2001

5. Califf RM, Armstrong PW, Carver JR, D'Agostino RB, Strauss WE. 27th Bethesda Conference: matching the intensity of risk factor management with the hazard for coronary disease events: Task Force 5. Stratification of patients into high, medium and low risk subgroups for purposes of risk factor management. J Am Coll Cardiol. 1996;27:1007-19.

6. Smith SC Jr, Allen J, Blair SN, et al. AHA/ACCF secondary prevention and risk reduction therapy for patients with coronary and other atherosclerotic vascular disease: 2011 update: a guideline from the American Heart Association and American College of Cardiology Foundation. JAm Coll Cardiol. 2011;58:2432-46.

7. Pearson TA, Blair SN, Daniels SR, et al., American Heart Association Science Advisory and Coordinating Committee. AHA guidelines for primary prevention of cardiovascular disease and stroke: 2002 update: consensus panel guide to comprehensive risk reduction for adult patients without coronary or other atherosclerotic vascular diseases. Circulation. 2002;106:388-91.

8. Buse JB, Ginsberg HN, Bakris GL, et al. Primary prevention of cardiovascular diseases in people with diabetes mellitus: a scientific statement from the American Heart Association and the American Diabetes Association. Circulation. 2007;115:114-26.

9. Adult Treatment Panel III. Third report of the National Cholesterol Education Program (NCEP) Expert Panel on Detection, Evaluation, and Treatment of
High Blood Cholesterol in Adults (Adult Treatment Panel III) final report. Circulation. 2002;106:3143-421.

10. Chobanian AV, Bakris GL, Black HR, et al. Seventh report of the Joint National Committee on Prevention, Detection, Evaluation, and Treatment of High Blood Pressure. Hypertension. 2003;42:1206-52.

11. King SB III, Aversano T, Ballard WL, et al. ACCF/AHA/SCAI 2007 update of the clinical competence statement on cardiac interventional procedures: a report of the American College of Cardiology Foundation/American Heart Association/American College of Physicians Task Force on Clinical Competence and Training (Writing Committee to Update the 1998 Clinical Competence Statement on Recommendations for the Assessment and Maintenance of Proficiency in Coronary Interventional Procedures). J Am Coll Cardiol. 2007;50 82-108.

12. Hillis LD, Smith P, Anderson J, et al. 2011 ACCF/AHA guideline for coronary artery bypass graft surgery: a report of the American College of Cardiology Foundation/American Heart Association Task Force on Practice Guidelines. $J$ Am Coll Cardiol. 2011;58:e123-210.

13. Levine GN, Bates ER, Blankenship JC, et al. 2011 ACCF/AHA/SCAI guideline for percutaneous coronary intervention: a report of the American College of Cardiology Foundation/American Heart Association Task Force on Practice Guidelines and the Society for Cardiovascular Angiography and Interventions. J Am Coll Cardiol. 2011;58:2550-83.

14. Gibbons RJ, Abrams J, Chatterjee K, et al. ACC/AHA 2002 guideline update for the management of patients with chronic stable angina: a report of the American College of Cardiology/American Heart Association Task Force on practice guidelines (Committee on the Management of Patients With Chronic Stable Angina). J Am Coll Cardiol. 2003;41:159-68.

15. Campeau L. Letter: grading of angina pectoris. Circulation. 1976;54:522-3.

16. Wright RS, Anderson JL, Adams CD, et al. 2011 ACCF/AHA focused update incorporated into the ACC/AHA 2007 guidelines for the management of patients with unstable angina/non-ST-elevation myocardial infarction: a report of the American College of Cardiology Foundation/American Heart Association Task Force on Practice Guidelines. J Am Coll Cardiol. 2011;57:e215-367.

17. TIMI Risk Score. Available at: http://www.timi.org. Accessed March 15, 2011

18. Tonino PA, De Bruyne B, Pijls NH, et al., for the FAME Study Investigators. Fractional flow reserve versus angiography for guiding percutaneous coronary intervention. N Engl J Med. 2009;360:213-24.

19. Chan PS, Patel MR, Klein LW, et al. Appropriateness of percutaneous coronary intervention. JAMA. 2011;306:53-61.

20. Chan PS, Brindis RG, Cohen DJ, et al. Concordance of physician ratings with the appropriate use criteria for coronary revascularization. J Am Coll Cardiol. 2011 57:1546-53

21. Dartmouth Atlas Project. Available at: http://www.dartmouthatlas.org. Accessed August 24, 2011.

22. Diamond GA. A clinically relevant classification of chest discomfort. J Am Coll Cardiol. 1983;1:574-5.

23. Antman EM, Hand M, Armstrong PW, et al. 2007 focused update of the ACC AHA 2004 guidelines for the management of patients with ST-elevation myocardial infarction: a report of the American College of Cardiology/American Heart Association Task Force on Practice Guidelines. J Am Coll Cardiol. 2008;51 210-47. 